\title{
Mechanism of 6061 Aluminium Material Erosion in USEMM
}

\section{WENJUN TONG}

Zhejiang University of Technology

\section{Kailei He}

Zhejiang University of Technology

\section{Xindi Wang}

Zhejiang University of Technology

\section{Xuefeng Xu}

Zhejiang University of Technology

Minghuan Wang ( $\square$ wangmh@zjut.edu.cn )

Zhejiang University of Technology

\section{Research Article}

Keywords: Ultrasonic-assisted electrochemical micromachining (USEMM), 6061Aluminium, Micro-jet, Passive layer, Erosion mechanism.

Posted Date: May 6th, 2021

DOl: https://doi.org/10.21203/rs.3.rs-463573/v1

License: (c) (i) This work is licensed under a Creative Commons Attribution 4.0 International License. Read Full License 


\title{
Mechanism of 6061 aluminium material erosion in USEMM
}

\author{
Wenjun Tong ${ }^{1}$, Kailei $\mathrm{He}^{1}$, Xindi Wang ${ }^{1}$, Xuefeng $\mathrm{Xu}^{1,2}$, Minghuan Wang ${ }^{1,2^{*}}$ \\ (1 College of Mechanical Engineering, Zhejiang University of Technology, Hangzhou 310014, Zhejiang, China \\ 2 Key Laboratory of Special Purpose Equipment and Advanced Processing Technology, Ministry of Education, \\ Zhejiang University of Technology, Hangzhou, 310014, Zhejiang, China) \\ *Correspondence: 18, Chaowang Road, Hangzhou 310014, China; E-mail: wangmh@zjut.edu.cn
}

\begin{abstract}
Micro-structure on metal surface can be created with high precision and good surface quality by ultrasonic-assisted electrochemical micromachining (USEMM). One of the prevalent material removal mechanisms in ultrasonic machining (UM) is cavitation erosion. However, the mechanism of material erosion is not clear and worth investigating. This study of the mechanical and chemical effects of the ultrasonic vibration in 6061 aluminium alloy is targeted to reveal the material processing mechanism in USEMM. Based on the built model, the velocity of micro-jet produced near the workpiece surface by ultrasonic cavitation reaches up to $350 \mathrm{~m} / \mathrm{s}$ when bubble collapses computed by software MATLAB. The impact of micro jet produces plastic micro-pits on the metal surface and the convex peak around the edge of the pits, which is verified in ABAQUS software. The metallographic microscope and curves of the electrochemical polarization behaviour results indicate a significant grain refinement and a marked increase of anodic dissolution current, as well as a weaker resistance than the original workpiece in $\mathrm{NaNO}_{3}$ electrolyte during UM. The current-time curve during machining demonstrates the passive layer forms on the metal surface and then breaks down at the time of less than 0.0066s in USEMM. Micrographs of scanning electron microscope (SEM) of the machined surface in different stages show that many uniform and flat pits are formed in USEMM, compared with the local uneven pits in EMM.
\end{abstract}

Keywords: Ultrasonic-assisted electrochemical micromachining (USEMM), 6061Aluminium, Micro-jet, Passive layer, Erosion mechanism.

\section{Introduction}

Recent progress achieved in the fields of tribology, heat transfer, air vehicle manufacturing and industrial chemistry has created a need for parts made of extremely hard or tough materials with meso 
or micro scale structured surfaces. The fabrication of micro structure has attracted considerable attention of the scholars in the field. For example, Hao et al. [1] proposed that the arrays of micro-concavities produced on the metallic planar and cylindrical inner surfaces are conducive to increase the dynamic pressure and decrease the resistance during the bearing running. Kumar et al. [2] found that the micro texture with a certain angle to the chip flow direction can reduce the friction coefficient and the tool stress during wire electrical discharge machining (WEDM).

Nowadays, several technologies have been employed to generate micro texture on metal surface, such as laser machining (LSM), micro-milling, micro-electrical discharge machining (EDM) and electrochemical micromachining (EMM). Among them, electrolysis-based EMM gains considerable advantages from removing materials, including a high material removal rate, absence of tool wear and no residual mechanical stress. EMM, as one of the preferred machining options for integral components [3], has been widely applied to machine various refractory materials. To date, EMM has developed and varied in its method, for example, electrochemical jet machining, an emerging interaction-based surface modification technique between an electrolyte jet and a conductive workpiece with an electrical potential, which is mainly employed to serve the jet and the workpiece between nozzles [4]. Martin et al. [5] studied the highly localized removal geometry, which can be produced due to the restricted distribution of the current density to a confined area by the electrolyte jet. Luo et al. [6] found it feasible to complete fabricating in a large-area surface by using tube electrodes in a row with a tube interval of $4.00 \mathrm{~mm}$, both denser crisscross and parallel grooves with a groove interval of $2.00 \mathrm{~mm}$ and a rare stray corrosion, and planning the tool path properly through electrochemical jet machining. Besides, through-mask electrochemical micromachining (TMEMM) is another promising method to generate arrayed surface texture, with the workpiece surface covered by a patterned mask through lithographic process and the machining region exposed [7]. Using this method, Wang et al. [8] gathered 30 micro grooves with different dimensions on titanium alloy surface. Air-shielding electrochemical micromachining (AS-EMM) can be counted as a third new processing for micro structure where the coaxial assistant gas supplies power to the radial electrolyte flow and keeps the hydraulic jump away from the jet impact area [9], so as to improve the localized material erosion [10].

Additionally, Ultrasonic-assisted electrochemical micromachining (USEMM) is a composite machining, combining ultrasonic vibration and EMM and characterized with high material removal rate and good machining performance. Singh et al.[11] proposed an ultrasonic vibration assisted 
electrochemical honing for bevel gear machining and found it optimizes the surface roughness of bevel gear by $91.04 \%$. Skoczypiec [12] suggested that the ultrasonic vibration potentially creates cavitation bubbles near the electrode and workpiece surface, and then intensifies mass and electric charge transportation. Goel [13] found that in the ultrasonic assisted jet electrochemical micro-drilling process, the material removal rate of the workpiece increased but the hole taper reduced with the ultrasonic vibration time. Mitchell-Smith et al. [14] presented their result that the ultrasonic assistance helps to improve the aspect ratio of the grooves, increase depth and reduce kerf achievable in multiple passes by nearly $6 \%$ and $7 \%$ respectively in single pass striations, due to the breakdown of passive layer. Ling et al. [15] confirmed that the ultrasonic vibration with proper amplitude reduces the slit width and improves the morphology of machined surface with the effect of ultrasonic vibration. Wang et al. [16] discovered that the electrode with ultrasonic vibration assistance enhances the machining efficiency and maximum depth of micro holes and the machined surface quality. Li et al. [17] also found more materials removed and good accuracy obtained in ultrasonic-assisted electrochemical drilling with high-speed electrode.

Nevertheless, EMM is still confronted with the main problems of the material removal rate and machined surface quality [16], while the mechanism of material erosion in USEMM is not clear, which all needs further research. Thus, this study attempts the mechanism of material erosion in USEMM by 6061 aluminium machining. Based on the theoretical model of cavitation bubble collapse, the variations of pressure and micro jet velocity at the boundary of bubbles are first computed by software MATLAB. Then, the plastic deformation on the workpiece surface based on the micro-jet is simulated in the software ABAQUS, the result of which is compared with those of other experiments. Finally, the metallographic and the electrochemical anodic dissolution behaviour is discussed in detail to reveal the processing mechanism in USEMM by series of experimental results.

\section{Theory}

\subsection{Description of the method}

Fig. 1 denotes the schematic diagram of material removal analysis during USEMM. As shown in Fig. 1(a), the ultrasonic vibrator is attached with cathode, while the anode is connected with the workpiece, which is dissolved by electrochemical machining. With the tool moving opposite to the workpiece in the process, the size of bubble increases when the electrolyte pressure decreases, and subsequently 
cavitation bubbles grow and promptly burst in Fig. 1(b). Contrastively, with the tool moving towards the workpiece, the bubble bursts near the anode surface and produces high-speed micro-jets, which is the main reason for cavitation damage following pressure waves. The bubbles burst asymmetrically near the wall of the workpiece, and the micro-jet directed toward the wall is generated on the sides of the faraway bubble. It should be noted that the passive layer formed on the surface of the workpiece can hinder the electrochemical reaction at a lower current density [19], while cavitation can effectively remove the passive layer from the workpiece surface and promote the circulation of electrolyte and the discharge of electrolyte products [20].

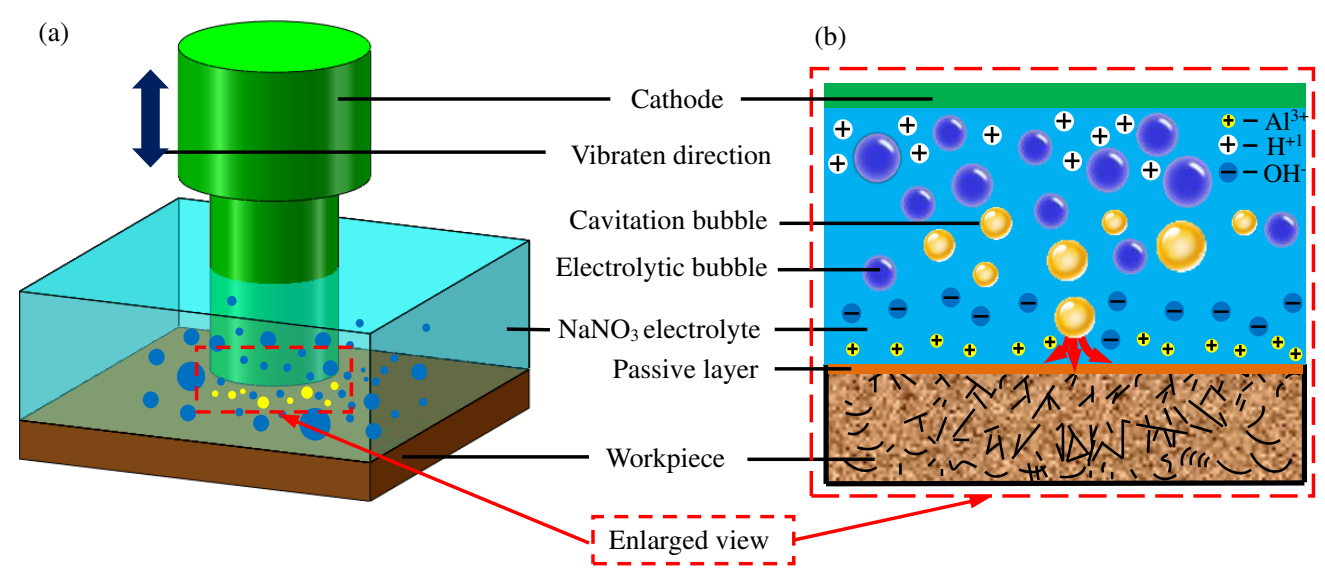

Fig. 1 Schematic model of material removal during USEMM

\subsection{Cavitation theory of USEMM}

During the USEMM, the tool electrodes vibrate along the axis of the ultrasonic vibrator, and cavitation effect occurs when incoming liquid ultrasonic sound pressure amplitude reaches the cavitation threshold in the $\mathrm{NaNO}_{3}$ solution electrolyte. The tiny nuclei in the liquid undergo growth, expansion, compression and collapse under the alternation of ultrasonic positive and negative pressure, but the velocity of micro-jet is accurately unobtainable, due to the complexity and randomness of the cavitation. According to the principle of conversation of energy, the bubble energy under actions of the external force $W$ can be converted to the kinetic energy $E_{\mathrm{k}}$ of the bubble and other energies $\varsigma \mathrm{E}$, that is

$$
W=E_{\mathrm{k}}+\Delta E
$$

If the bubble oscillation is assumed to be a vibrator regarding the liquid as a load, the function $E_{\mathrm{k}}$ can be expressed as, 


$$
E_{k}=\int_{R}^{\infty} \frac{1}{2} \rho\left(\frac{R^{2} d R}{r^{2} d t}\right)^{2} 4 \pi r^{2} d r
$$

Where $R$ is the radius of the bubble, $\rho$ is the density of the liquid, $t$ is the cavitation bubble movement time and $r$ is the distance from the center of the bubble. Besides, the external force $W$ on the bubble can be represented as,

$$
\begin{aligned}
& W=-\int_{R_{0}}^{R} P .4 \pi R^{2} d R \\
& P=\left(P_{0}+\frac{2 \sigma}{R_{0}}-P_{v}\right)\left(\frac{R_{0}}{R}\right)^{3 \kappa}+P_{v}+P_{A} \sin 2 \pi f t-P_{0}-\frac{2 \sigma}{R}-\frac{4 \mu}{R} \frac{d R}{d t}
\end{aligned}
$$

Where $P_{0}$ is the standard atmospheric pressure, $\sigma$ is the liquid surface tension, $R_{0}$ is the initial radius of bubble, $P_{\mathrm{v}}$ is the vapor pressure of bubble, $f$ is the ultrasonic frequency, $\kappa$ is the adiabatic index, $P_{\mathrm{A}}$ is the amplitude of the ultrasonic sound pressure, which is nearly $0.87 \mathrm{MPa}$ [21], and $\mu$ is the liquid viscosity. Substituting Eqs. (2)-(4) into Eqs. (1), and ignoring the term $§ E$, the model describing the radial dynamic characteristic of the cavitation bubble under USEMM can be derived as:

$$
R \frac{d^{2} R}{d t^{2}}+\frac{3}{2}\left(\frac{d R}{d t}\right)^{2}=\frac{1}{\rho}\left[\left(P_{0}+\frac{2 \sigma}{R_{0}}-P_{v}\right)\left(\frac{R_{0}}{R}\right)^{3 \kappa}\right]+\frac{1}{\rho}\left[P_{v}-P_{0}+P_{A} \sin 2 \pi f t-\frac{2 \sigma}{R}-\frac{4 \mu}{R} \frac{d R}{d t}\right]
$$

The theoretical data of ultrasonic cavitation are simulated and analyzed by the Runge-Kutta method of 4-5steps through MATLAB software, as shown in Table 1.

Table 1 Matlab analysis parameters

\begin{tabular}{lll}
\hline Parameter & Unit & Value \\
\hline Vapor pressure of bubble & $\mathrm{Pa}$ & 2330 \\
Frequency $(f)$ & $\mathrm{kHz}$ & 28 \\
Atmospheric pressure & $\mathrm{Pa}$ & 101320 \\
Liquid surface tension & $\mathrm{N} / \mathrm{m}$ & 0.0725 \\
Liquid viscosity $(\mu)$ & $\mathrm{Pa} . \mathrm{s}$ & 0.001 \\
Liquid density $(\rho)$ & $\mathrm{kg} / \mathrm{m}^{3}$ & 937 \\
Initial radius of bubble & $\mu \mathrm{m}$ & 12.5 \\
Adiabatic index $(\kappa)$ & & $4 / 3$ \\
\hline
\end{tabular}

Fig. 2 depicts the cavitation bubble burst in the machining gap, which clearly shows that the cavitation bubble undergoes expansion, compression, oscillation and collapse in one cycle. When the bubble radius is compressed infinitely close to zero as in Fig 2a, the highest velocity of micro-jet will reach close to $350 \mathrm{~m} / \mathrm{s}$, the whole process of which will occur within one circle as shown in Fig. $2 \mathrm{~b}$. 
(a)

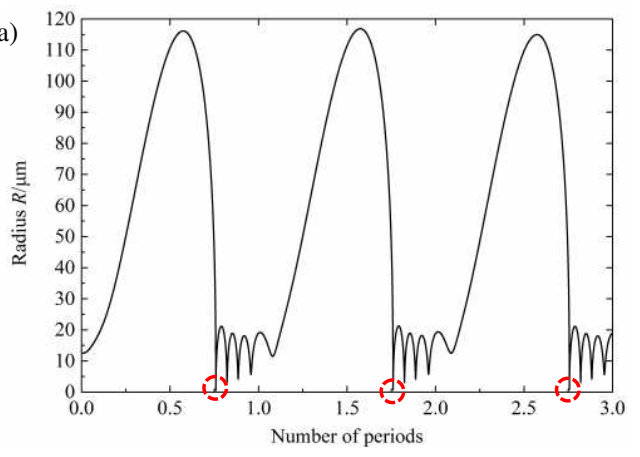

(b)

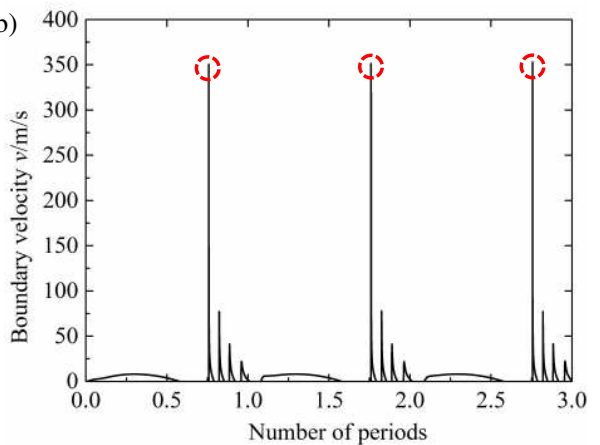

Fig. 2 Analysis of cavitation bubble collapse (a) Radius, (b) Velocity

\subsection{Removal theory of USEMM}

According to the EMM, the electrolyte conductivity is a main factor for electric current distribution in the interelectrode gap and influenced by the products between the narrow machining gaps, such as hydrogen and sludge. Considering the influence of the void rate of hydrogen on the electrolyte conductivity, the material dissolution formula can be built as,

$v_{\mathrm{a}}=\eta \omega \kappa E=\eta \omega \kappa \frac{\Delta U}{\Delta_{\mathrm{b}}}$

Where $\eta$ is the current efficiency of anodic dissolution, $\omega$ is the electrochemical equivalent of the workpiece material, $\kappa$ is the electrolyte conductivity with tool vibration, $E$ is the electric field intensity, $\Delta U$ is the total overpotential between cathode and anode and $\Delta_{\mathrm{b}}$ is the frontal gap. Considering the conductivity of electrolyte, Fujisawa et al. [22] conducted the formula due to heating and gas generation as follows,

$\kappa=\kappa_{0}\left[1+0.016\left(T(x)-T_{0}\right)\right][1-\beta]^{1.75}$

Where $\kappa_{0}$ is the original value of electrolyte conductivity, $T_{0}$ is the original temperature and $\beta$ is the void fraction of gas in the machining gap. During the USEMM, the tool vibrates at the equilibrium position while the frontal machining gap varies periodically. The frontal gap between micro-tool and the workpiece can be described as,

$$
\Delta_{\mathrm{z}}=\Delta_{\mathrm{b}}+A \cos (\omega \mathrm{t}+\varphi)
$$

Where $\Delta_{\mathrm{z}}$ is the equilibrium gap, $\omega$ is the angular velocity and $\varphi$ is the phase symbol. According to the theoretical model under the influences of the electric field and the I law of Faraday defined machining gap in USEMM, material removal rate (MRR) is noted as, 
$\mathrm{MFR}=\frac{\eta M}{n F}=\frac{\eta M \kappa \Delta U S}{n F \Delta_{z}}=\frac{\eta M \Delta U S \kappa_{0}\left[1+0.016\left(T(x)-T_{0}\right)\right][1-\beta]^{1.75}}{n F\left(\Delta_{b}+A \cos (\omega t+\varphi)\right)}$

Where $I$ is the current density in the machining gap, $M$ is the molar mass, $n$ is the valence of substance, $F$ is the Faraday constant and $S$ is the machining area. The equilibrium temperature and the machining gap can be measured experimentally. Based on equation (9), the theoretical material removal rate of the micro-jet acting on the workpiece surface will be obtained, and increase with the tool vibration during USEMM.

\section{Physical model and simulation}

\subsection{Micro-jet impinging model description}

As discussed above, there will be a large number of micro-jets with nearly $350 \mathrm{~m} / \mathrm{s}$ velocity impinging on the wall continually. To examine their impact, this study employed the large-scale finite element analysis ABAQUS software and the coupling method of smoothed particle hydrodynamics and finite element method (SPH-FEM) for a thorough analysis. It should be noted that due to the extremely short process, the heat exchange and water vaporization are excluded from the numerical model, as is shown in Fig. 3.

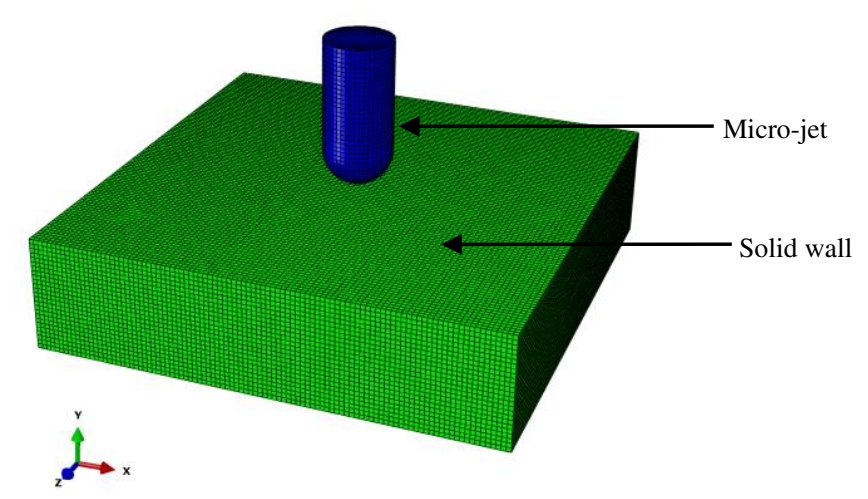

Fig. 3 SPH-FEM coupling model of micro-jet

According to the specific working conditions of USEMM, 6061 aluminium alloy with 145MPa Yield strength and $69000 \mathrm{MPa}$ Young's modulus can be used for an accurate expression of the plastic deformation results, while $\mathrm{NaNO}_{3}$ solution with $10 \mathrm{wt} . \%$ concentration selected as the mixture liquid in this paper. Moreover, the micro-jet with $6 \mu \mathrm{m}$ diameter and $13 \mu \mathrm{m}$ length impinges the wall vertically at a speed of $350.0 \mathrm{~m} / \mathrm{s}$, and the aluminum plate is assumed with size of $40 \times 40 \times 10 \mu \mathrm{m}$ [23]. Seeing that, 
this study defined the cell type to PC3D and the total number of particles to 99964 . The selected in this experiment also include the elastic-plastic solid plate, which is fixed around, and the sinusoidal ultrasonic pressure in the modeling area.

\subsection{Simulation results and analysis}

Fig. 4 shows the simulation topography and profiles of cross-section from 0 to $75 \mathrm{~ns}$. It can be seen that the plastic deformation occurs on the surface of the 6061 aluminium alloy and the material on pits side uplifts plastically with the impacting effect of the micro-jets, as detailed in Fig. 4(a)-(d). According to the color scale, the edge height and depth of the pit formed by the micro-jet increased with the increase of time, but unchaged in 75ns in Fig. 4(e).
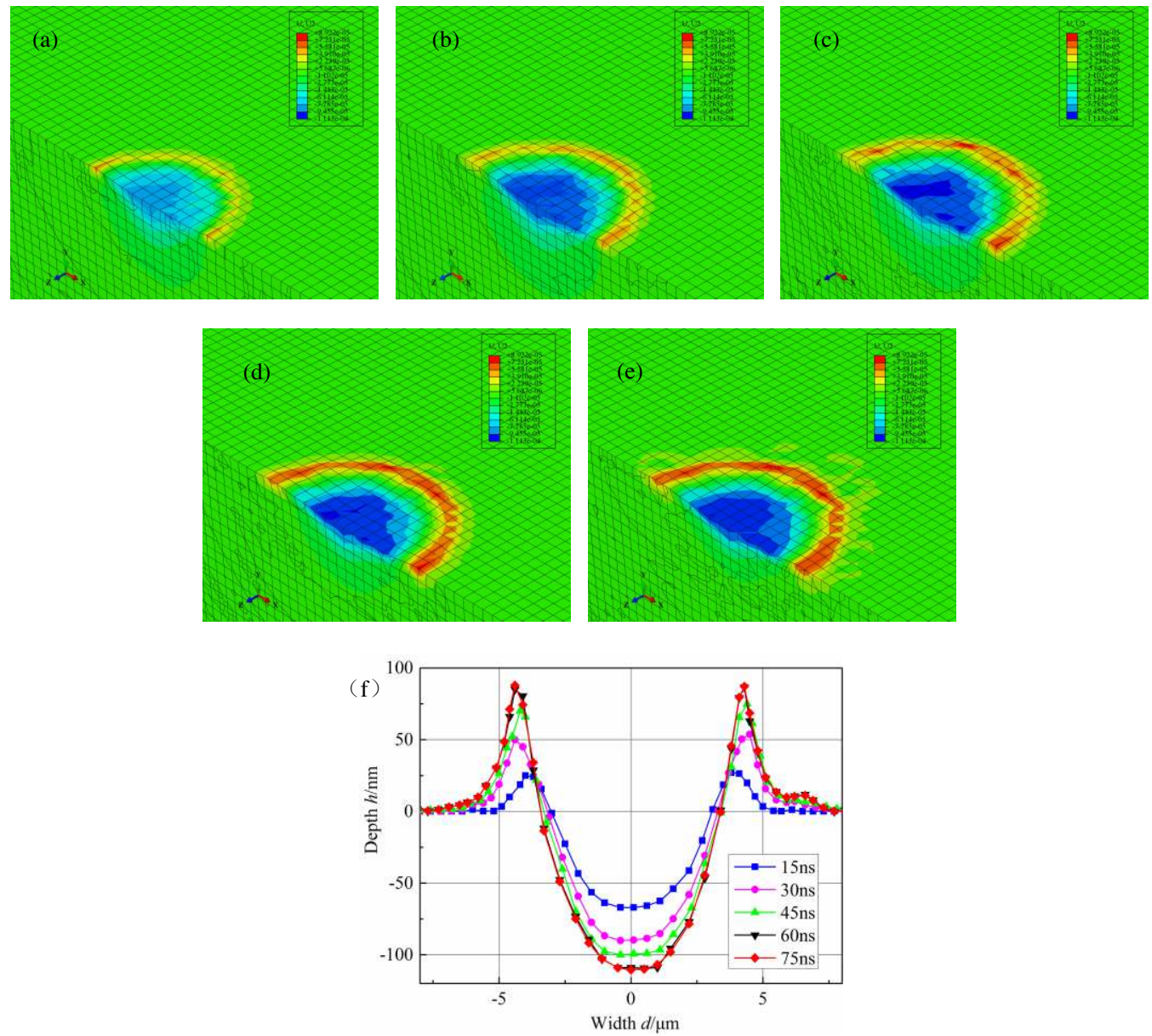

Fig. 4 Simulation topography and profiles of cross-section at different time:

(a) $15 \mathrm{~ns}$, (b) $30 \mathrm{~ns}$, (c) $45 \mathrm{~ns}$, (d) 60ns, (e) $75 \mathrm{~ns}$

Fig. 4(f) demonstrates that after the impingement of micro-jets, small round pits appear on the wall and plastic bulges surround the edge of the workpiece surface. With the increase of simulation time, the 
geometry size of generated pits increases accordingly, but keeps unchanged at 75ns, where the depth of the pits is $111.3 \mathrm{~nm}$ and the height of the peak is $89.12 \mathrm{~nm}$. Despite the very limited impact time of a single micro-jet with just several nanoseconds, a large number of micro-jets continually impinge on the wall during the whole process of USEMM. Thus, micro-jets should not be underestimated, since whose impacting effect possibly contributes to a higher materials' removal rate in the electrochemical micromachining.

\section{Experimental}

\subsection{Experimental set-up}

Fig. 5 schematically illustrates the specially developed machining set-up. The experimental system consists of ultrasonic vibration unit, power supply unit, motion control unit, data acquisition unit and detection unit. The first unit mainly includes an ultrasonic transducer with $28 \mathrm{kHz}$ pulse frequency and $10 \mu \mathrm{m}$ amplitude, which functions to transform the ultrasonic signal into the micro-protrusion for the cavitation. The tool or workpiece with $100 \mu \mathrm{m}$ machining gap is controlled by machine tool based on its control unit, while machining voltage is supplied by a DC power supply with $10 \mathrm{~V}$ voltage. Besides, the electric signal and machining zone is detected by oscilloscope and high-speed camera correspondingly. With the average of three tests for each parameter setting, micro-texture machining is processed on the sample for the duration of specified time. Electrode dressing is performed to improve the form accuracy by wire electro discharge grinding (WEDG) after each machining cycle.

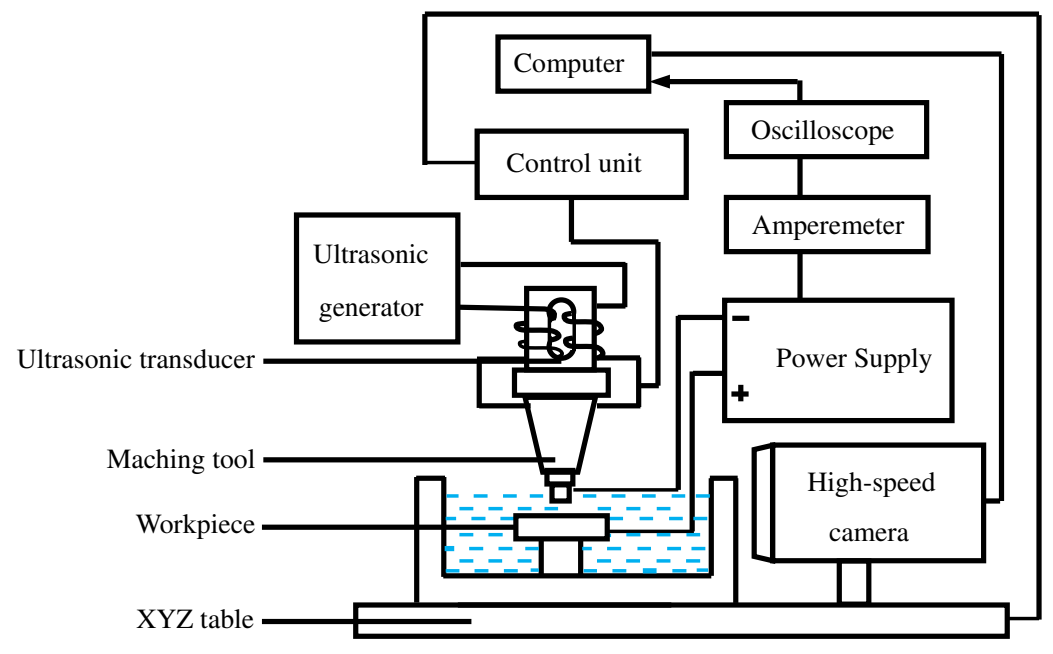

Fig. 5 Schematic diagram of the experimental equipment 


\subsection{Measurement and evaluation}

This study adopted a scanning electron microscope (SEM), Sigma HV-01-43, Zeiss, Germany, to examine the micro structure of the samples as well as the surface topography of the machined micro-texture. Specifically, the material composition of the machined surface was analyzed by the Energy-dispersive X-ray spectroscopy (EDX), the 3D views and the profile by a 3D surface profiler (VHX-7000), and the roughness by an Optical profilometer (SuperView W1). Furthermore, tool electrode movement in the Z-direction during machining test was captured using a Keyence high speed camera to describe the machining stability, while KEYENCE VW6000 Motion Analyzer software was used to track the movement of the electrode and the ultrasonic amplitude, and a metallurgical Microscope (Leica DM6 M-Leica DM6 M) used to study the microstructure of specimens. Lastly, the anodic dissolution behavior of the processed samples were analyzed by CHI600A Electrochemical workstation, and the relevant oscilloscope (Tektronix, TBS1000B, Shanghai, China), current amplifier (TCPA300), current probe (TCP312A) were chosen to measure the current change in the machining gap.

\section{Results and discussion}

\subsection{Mechanical effect of ultrasonic vibration}

\subsubsection{Plastic deformation by micro-jets}

For a close observation of the structure of the machining surface, this study machined the 3D topography of workpiece surface mapped with $500 \times 500 \mu \mathrm{m}$ areas under the same machining parameters in 0.1s with and without ultrasonic machining, which is shown in Fig. 6. It is clear that the whole workpiece surface looks smooth (Figs. 6a and 6b). During the US, the surface becomes uneven with many dense pits as the micro-jets continue to impinge on the original workpiece, as shown in Fig. 6(c)-(e). Fig. 7 reveals the comparison of micro dimple profiles with ultrasonic machining between simulation and experimental results. The experimental size of the pits are relatively uniform, with the average width of $8.4 \mu \mathrm{m}$, height of $90 \mathrm{~nm}$ and depth of $110 \mathrm{~nm}$, which denotes a similar variation during the US to the former result. It deserves a mention that the deviation between the two results is $9.7 \%$ and $3.2 \%$ in the diameter and depth correspondingly. 


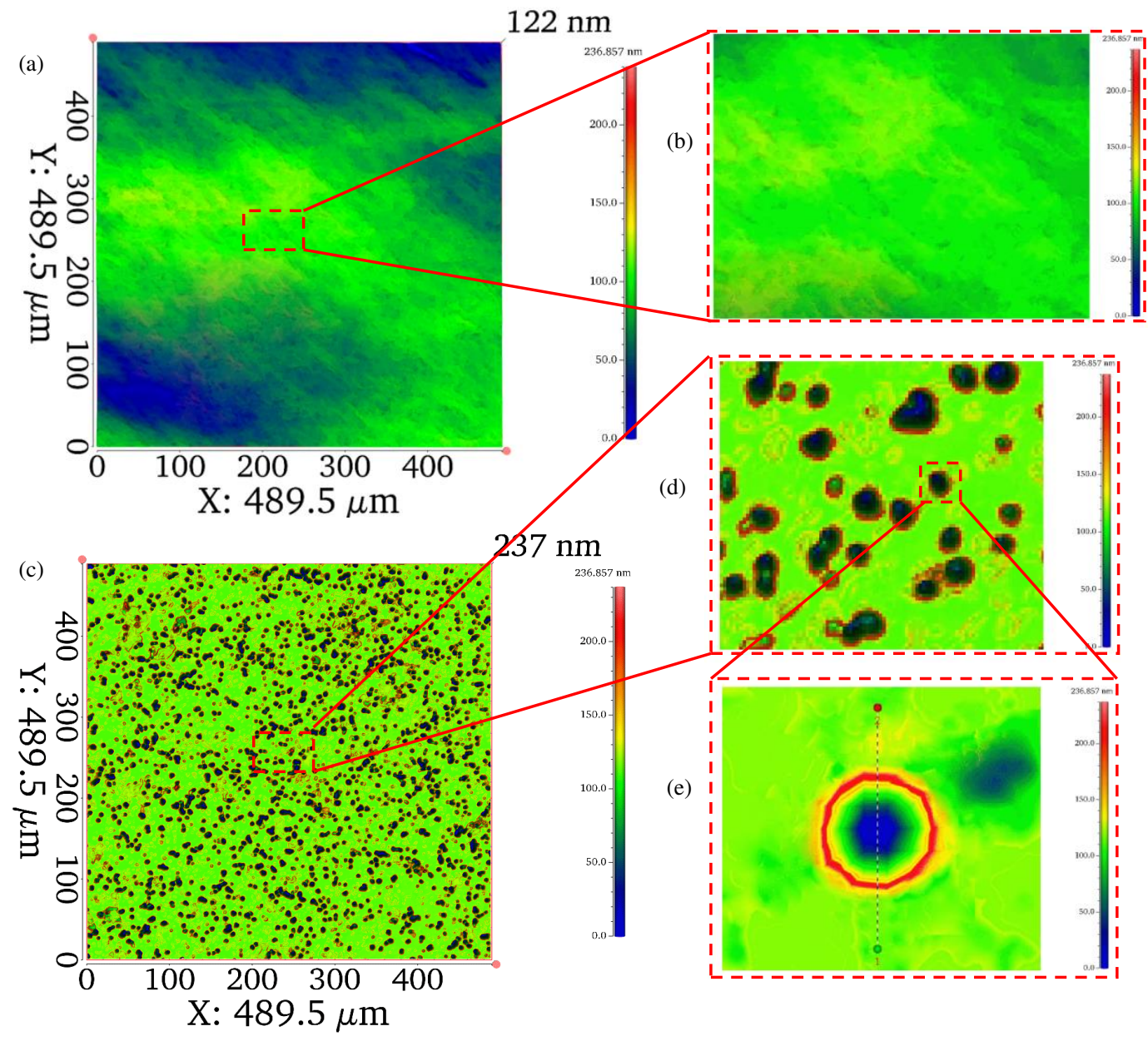

Fig 6 Micrographs of machined surfaces after $0.1 \mathrm{~s}$

Without ultrasonic:(a)、(b); With ultrasonic: (c)、(d)、(e)

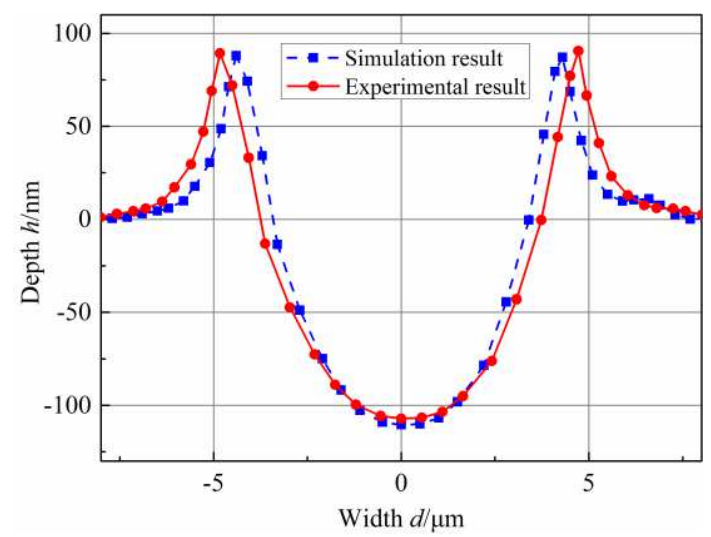

Fig. 7 Experimental and simulation profiles of micro dimples with ultrasonic machining

\subsubsection{Grain distribution}

The plastic deformation of the workpiece is caused by the micro-jets. Fig. 8 shows the $30 \mu \mathrm{m}$ and $50 \mu \mathrm{m}$ before and after ultrasonic machining. The grain color is different due to the different orientation of the 
corrosion resistance in the corrosion of the corrosion agent. According to this figures, the relevant average and maximum grain size of the original workpiece surface is nearly $50 \mu \mathrm{m}$ and $80 \mu \mathrm{m}$ correspondingly, as seen in Fig. 8(a), whereas those of the deformed are $30 \mu \mathrm{m}$ and $50 \mu \mathrm{m}$ respectively, as shown in Fig. 8(b). It also indicates the effectiveness of ultrasonic cavitation in refining the grain size.

(a)

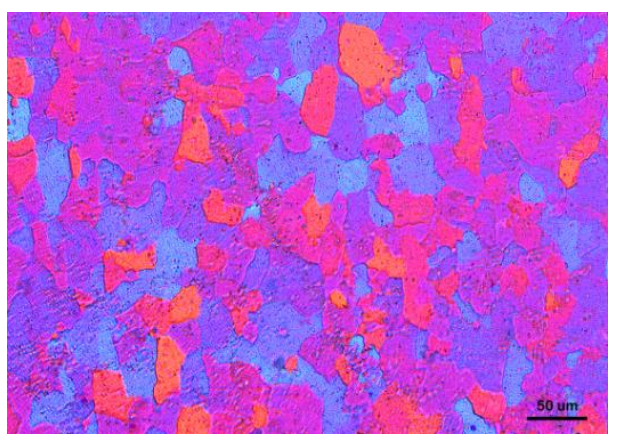

(b)

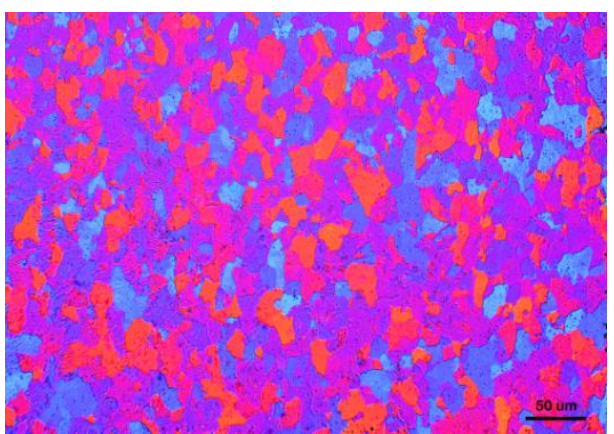

Fig. 8 Grain size morphologies before and after ultrasonic machining

\subsection{Chemical effect of ultrasonic vibration}

\subsubsection{Electrochemical polarization behavior}

The anodic dissolution behaviors of the original and ultrasonic vibration processed samples were analyzed by polarization characteristic and electrochemical impedance spectroscopy (EIS). All the experiments were performed in a $10 \mathrm{wt} . \% \mathrm{NaNO}_{3}$ solution, with the nearly $4 \mathrm{~cm}^{2}$ exposed area of the working electrode with the solution. The potentiodynamic polarization curves were obtained at a scan rate of $1 \mathrm{mV} / \mathrm{S}$ from $-400 \mathrm{mV}$ to $100 \mathrm{mV}$ versus open circuit potential as the electrochemical testing system became stable (about $60 \mathrm{~min}$ ). Besides, the EIS tests were conducted by sweeping frequencies from $100 \mathrm{kHz}$ to $10 \mathrm{mHz}$ with an $\mathrm{AC}$ voltage amplitude of $10 \mathrm{mV}$, and each electrochemical test was repeated three times to ensure its reproducibility. Fig. 9(a) depicts the polarization characteristic curves during the immersion in $\mathrm{NaNO}_{3}$ solution at room temperature. Compared with the original one, the ultrasonic cavitation processed sample shows a distinct cathode shift at the anodic dissolution potential $\mathrm{E}_{\text {corr }}\left(137 \mathrm{mV}\right.$ shift in active direction) and a significant increase of current density $\mathrm{i}_{\text {corr }}$. Consequently, the workpiece with the same processing has a lower corrosion resistance, which means a more likely anodic dissolution reaction and a higher velocity of anodic dissolution than the original workpiece surface during the EMM [24]. 

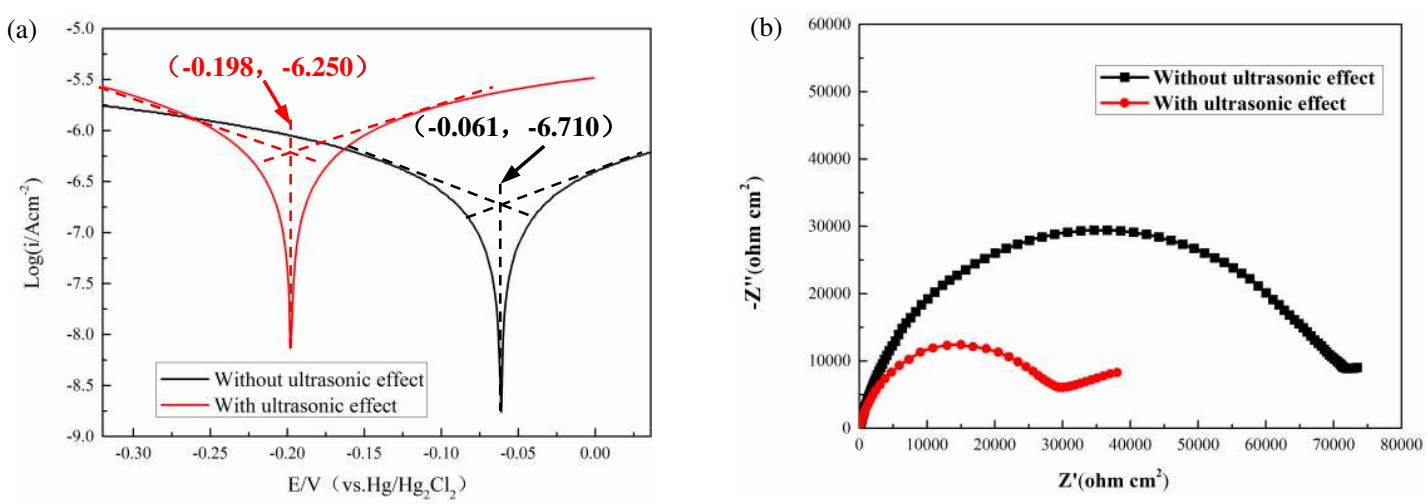

Fig. 9 Polarization characteristic and Nyquist plots of impedance curves in different conditions

Fig. 9(b) shows the Nyquist diagrams obtained from EIS tests for the original and ultrasonic cavitation processed samples. As is seen, two capacitive arcs are presented by the samples at the intermediate frequency with and without the ultrasonic effect respectively, which can be attributed to the metal dissolution. Moreover, the diameter of the capacitive arc of the ultrasonic samples is much smaller than that of the original, which might contribute to the influence of the charge transfer resistance, i.e. the corrosion resistance [25].

\subsubsection{Passive layer breakdown}

As mentioned above, the studies of the electrochemical anodic dissolution behavior reveal that the ultrasonic cavitation processed samples have a weaker anodic dissolution resistance, which means that the electrochemical reaction is more likely to occur [25]. From the current-time curves by oscilloscope and current probe shown in Fig. 10, it appears the plateau regions of the currents, which indicates the existence of a breakdown time for the passive layer. Not only that, this breakdown time decreases with the ultrasonic cavitation from $0.0415 \mathrm{~s}$ to $0.0066 \mathrm{~s}$, due to the continual impacting effect of micro-jets on the workpiece surface. During the EMM, the current density decreases to nearly $11.693 \mathrm{~A} / \mathrm{cm}^{-2}$, when the machining time is over $0.181 \mathrm{~s}$ and which will stay relatively stable for a period. Later, the decreasing tendency will continue till the value reaches $14.553 \mathrm{~A} / \mathrm{cm}^{-2}$, which might be the result of the progressive increase of the machining gap during the USEMM. 


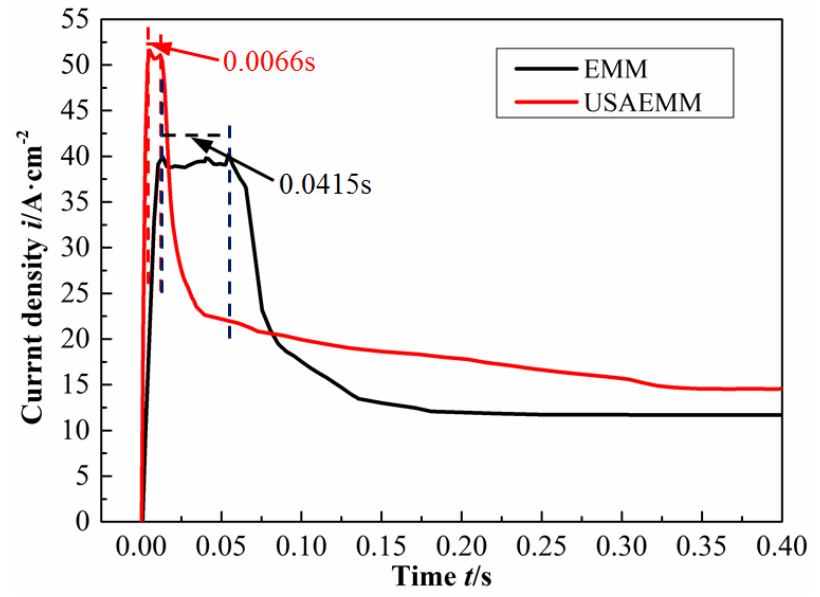

Fig. 10 Current-time curve for the breakdown of the passive layer by EMM and USEMM

\subsection{Material erosion process}

Fig. 11 shows the SEM images of the machined surfaces at different time. From Fig. 11(a), it can be seen that the bare metalareas are found on the specimen surface, indicating local break-down of the passive film and the visible metal anodic dissolution pits appears after 0.1s. The electrochemical machining initiates its reaction on the surface of workpiece, which will lead to an unstable machining process and a reduction of material removal rate. When the anodic dissolution time comes at $0.2 \mathrm{~s}$ (Fig. 11(b)), bare metal areas and coarse surface is hard to find on the specimen surface, showing that the electrochemical dissolution is progressing further. Afterwards, the active metal dissolution occurs on the specimen surface at $0.6 \mathrm{~s}$ with bare metal areas not found, as shown in Fig. 11(c). The on-going impacting effect of micro-jets by ultrasonic cavitation generates a great many dense anodic dissolution pits and products on the surface of 6061 aluminum alloy during the USEMM, which is completely different in the EMM. From Fig. 11(d)-(f), it can be seen that the diameter and the flatness of the pits increase with the machining time from 0.1 to $0.6 \mathrm{~s}$. Besides, with the removal of the anodic dissolution products under the constant impacting effect and finally that of the machined peaks by electrochemical micromachining, the anodic dissolution on the workpiece surface tends to be uniform and then the surface to be smooth. 
(a)

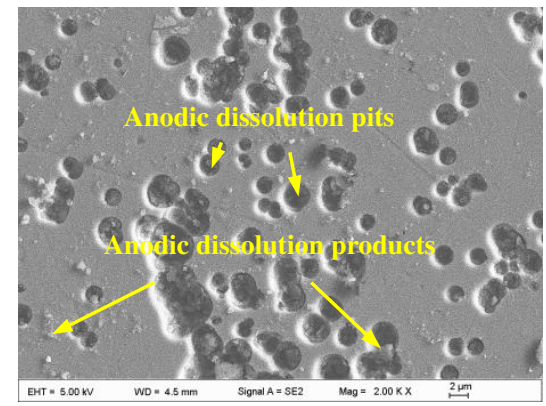

(b)

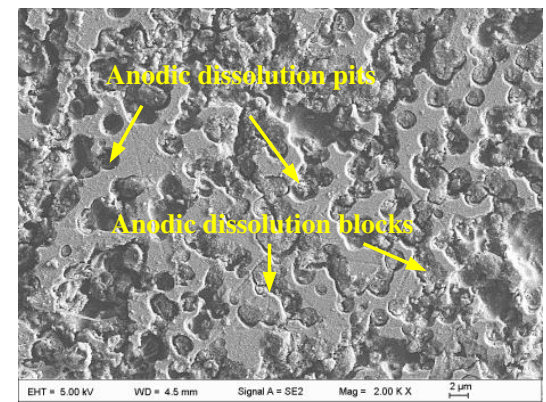

(c)

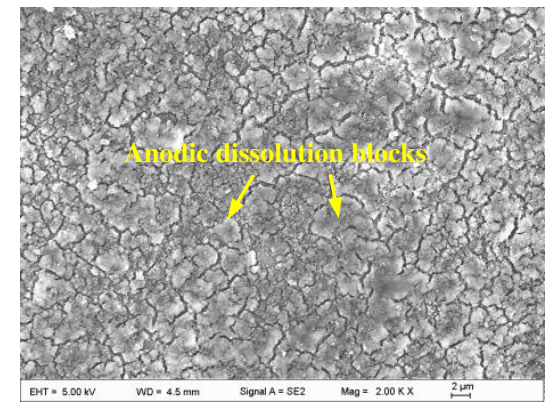

(d)

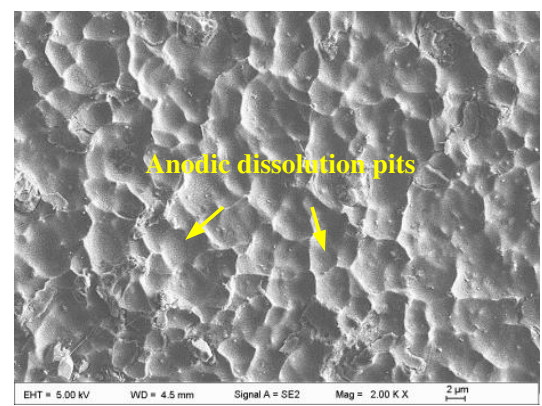

(e)

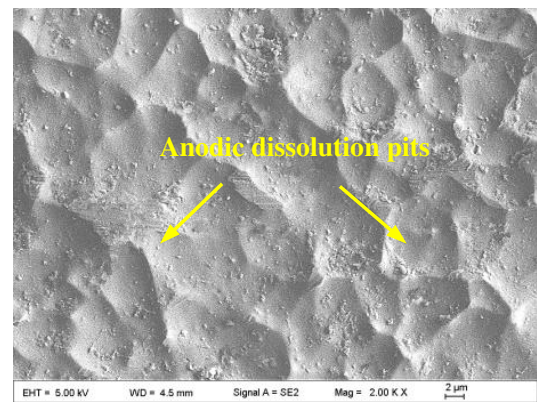

(f)

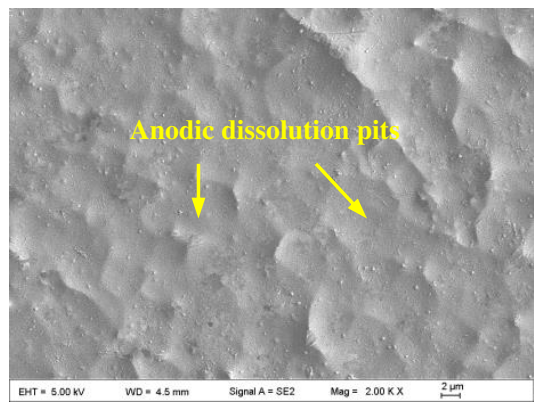

Fig. 11 SEM images of surface structures anodically dissolved at different time $(0.1,0.2,0.6 \mathrm{~s})$

EMM:(a), (b), (c); USEMM: (d), (e),(f)

\subsection{Process mechanism}

On basis of all the experimental results discussed above, this study developed a qualitative model to illustrate the material erosion mechanism of USEMM process, as shown in Fig. 12. The state of the machining gap in the USEMM process is described in the partially enlarged Fig. 12 (a). It is apparent that the plastic pits form on the workpiece surface by the constant high-speed micro-jets, resulting in the removal of passive layer in the $\mathrm{NaNO}_{3}$ solution electrolyte. Besides, convex peaks can be seen around the edge of the pits and the electric field is more concentrated, which produces an increase of the current density in the machining gap. However, with the rapid electrochemical dissolution of anode material, near the surface wall are adsorbed a growing number of reactive metal ions, hydroxide ion and highly-adhered electrolytic products. Fig. 12 (b) manifests the anodic dissolution pits of the different depths formed on the surface of the anode, which decreases the surface roughness and aggravates the agglomeration of the surface products. Fig. 12(c) shows the highly-adhered electrolytic 
products, which are quickly removed from the machining gap by the high speed micro-jets to expose the new metal surface due to the strong scouring of electrolyte by high-speed micro-jet. It can be summarized that the whole surface morphology and flatness are markedly increased under the comprehensive effect of the micro-jets on the workpiece surface during USEMM.

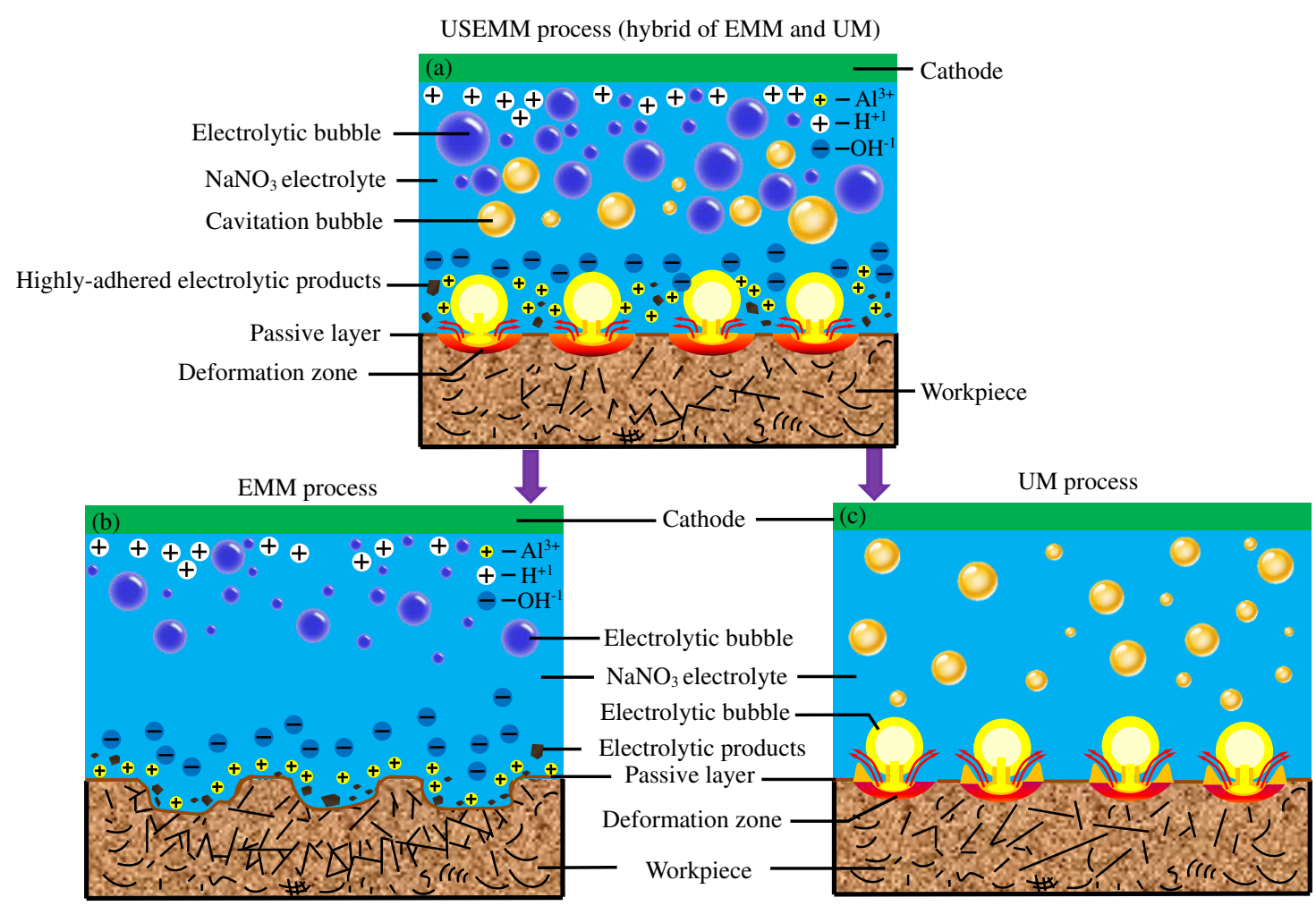

Fig. 12 Schematic model of material anodic dissolution during USEMM

USEMM: (a); EMM: (b); UM: (c)

\section{Conclusion}

This paper presents a study of the mechanism of 6061 aluminium material erosion in USEMM in the machining gap through both mechanical and chemical effects, the method on surface flatness and erosion behavior of the samples as well as the mechanism of the coupling effect. Based on these analyses, it can be concluded as follows:

(1) Simulation results provide an explanation for a real trial. The velocity of micro-jet produced near the wall can reach up to $350.0 \mathrm{~m} / \mathrm{s}$ when bubble collapses, while pits appear on the surface of the 6061 aluminium alloy under the impacting effect of micro-jets through MATLAB and ABAQUS software. Besides, according to the average deviation of less than $9.7 \%$ between experimental and theoretical results obtained through surface topography analysis, simulation results is in close accordance with the experimental. 
(2) During the USEMM process, the ultrasonic cavitation triggers a series of reactions and produces corresponding products: at first the micro-jets, and then the plastic micro-pits on the metal surface as well as the convex peaks around the edge of the pits. Subsequently, the plastic peaks enhance the impact of the electric field in the machining gap, where occurs the first anodic dissolution instead of a direct electrochemical machining reaction on the surface of workpiece, then bringing a better and smoother surface.

(3) The ultrasonic cavitation processed workpiece has a finer grain refinement, a weaker anodic dissolution resistance, a substantial cathode shift at $E_{\text {corr }}$ as well as a significant increase of $i_{\text {corr }}$ than the original workpiece without any treatment . It implies that the former is more likely to be anodically dissolved by EMM.

(4) During the USEMM generates a passive layer on the surface of metal specimen, which breaks down at the time of less than 0.0066 s under the continuous impacting effect of the micro-jets. Besides, the anodic dissolution current density increases greatly.

(5) The removal effect of the micro-jets on passive layer results in the formation of a large quantity of uniform and flat pits on the surface of workpiece, instead of the anodic dissolution of local uneven pits at different time in EMM.

Author contribution All authors contributed to the research, writing, and reviewing of the paper.

Data availability The authors confirm that the data supporting this study are available within the article.

Code availability Custom codes where implemented in the software as explained in details in the manuscript.

\section{Declarations}

Competing interests The authors declare no competing interests.

Ethics approval Not applicable

Consent to participate Not applicable

Consent for publication All authors have agreed to authorship, read, and approved the manuscript, and given consent for submission and subsequent publication of the manuscript. The authors guarantee that the contribution to the work has not been previously published elsewhere 
Funding The authors would like to thank the financial support of the projects from the Zhejiang Provincial Natural Science Foundation [grant numbers LY19E050007] and the National Natural Science Foundation of China [grant numbers 51975532, 51475428].

\section{References}

[1]. X. Hao, L. Wang, D. Lv, Q. Wang, L. Li, N. He, B. Lu. Fabrication of hierarchical structures for stable superhydrophobicity on metallic planar and cylindrical inner surfaces. J. Appl. Surf. Sci. 325 (2015) 151-159.

[2]. C.S. Kumar, S.K. Patel. Effect of WEDM surface texturing on Al2O3/TiCN composite ceramic tools in dry cutting of hardened steel. Ceramics International. 44 (2018) 2510-2523.

[3]. X. Hu, D. Zhu, J. Li, Z. Gu. Flow field research on electrochemical machining with gas film insulation. J. Mater. Process. Technol. 267 (2019) 247-256.

[4]. I. Bisterov, J. Mitchell-Smith, A. Speidel, A. Clare. Specific and programmable surface structuring by electrochemical jet processing. 68 (2018) 460-465.

[5]. A. Martin, M. Hackert-Oschätzchen, N. Lehnert, A. Schubert. Analysis of the fundamental removal geometry in electrochemical profile turning with continuous electrolytic free jet. Procedia Cirp. 68 (2018) 466-470.

[6]. J. Luo, X. Fang, D. Zhu. Jet electrochemical machining of multi-grooves by using tube electrodes in a row. J. Mater. Process. Technol. 283 (2020) 116705.

[7]. X.L. Chen, G.C. Fan, C.H. Lin, B.Y. Dong, Z.N. Guo, X.L. Fang, N.S. Qu. Investigation on the electrochemical machining of micro groove using masked porous cathode. J. Mater. Process. Technol. 276 (2020) 116406.

[8]. G.Q. Wang, D. Zhu, H.S. Li. Fabrication of semi-circular micro-groove on titanium alloy surface by through-mask electrochemical micromachining. J. Mater. Process. Technol. 258 (2018) 22-28.

[9]. M. Wang, Z. Bao, G. Qiu, X. Xu. Fabrication of micro-dimple arrays by AS-EMM and EMM. Int J Adv Manuf Technol. 93 (2017) 787-797.

[10]. M.H. Wang, W.J. Tong, G.Z. Qiu, X.F. Xu, A. Speidel, J. Mitchell-Smith. Multiphysics study in air-shielding electrochemical micromachining. J. Mater. Process. Technol. 43 (2019) 124-135.

[11]. H. Singh, P.K. Jain. Study on ultrasonic-assisted electrochemical honing of bevel gears. Proc IMechE Part B: J Engineering Manufacture. 232 (2018) 705-712. 
[12]. S. Skoczypiec. Research on ultrasonically assisted electrochemical machining process. Int J Adv Manuf Technol. 52 (2011) 565-574.

[13].H. Goel, P.M. Pandey. Experimental Investigations and Statistical Modeling of Ultrasonic Assisted Jet Electrochemical Micro-Drilling Process with Pulsed DC. Journal of Advanced Manufacturing Systems. Vol. 18, No. 3 (2019) 431-434.

[14].J. Mitchell-Smith, A.T. Clare. ElectroChemical Jet Machining of Titanium: Overcoming Passivation Layers with Ultrasonic Assistance. 42 (2016) 279-383.

[15].S. Ling, M. Li, Y. Liu, K. Wang, Y. Jiang. Improving Machining Localization and Surface Roughness in Wire Electrochemical Micromachining Using a Rotating Ultrasonic Helix Electrode. Micromachines. 11 (2020) 698.

[16]. M. Wang, Y. Zhang, Z. He, W. Peng. Deep micro-hole fabrication in EMM on stainless steel using diskmicro-tool assisted by ultrasonic vibration. J. Mater. Process. Technol. 229 (2016) 475-483.

[17]. M. Li, Y. Liu, S. Ling, K. Wang, Y. Jiang. Theoretical and experimental study on micro ultrasonic-assisted electrochemical drilling with high speed electrode. Int J Adv Manuf Technol. 107 (2020) 815-826

[18]. X. Zhu, Y. Liu, H. Kong. Experimental Study on Ultrasonic Vibration assisted Electrochemical Grinding of Small Holes *. Proceeding of the IEEE International Conference on Robotics and Biomimetics. 2019.

[19]. Y. Zhu, B. Wu, N. Yun. Basic Research on Ultrasonic Electrolysis Composite Micromachining of Micro Devices. Journal of Electric Machining and Mold. 2 (2006) 56-59.

[20]. S. Skoczypiec, A. Ruszaj. Discussion of cavitation phenomena influence onelectrochemical machining process. Int. J. Manuf. Sci. Technol. 7 (2005), 27-32.

[21]. M. Wang, X. Chen, W. Tong, J. Wang, X. Wang. Influences of gap pressure on machining performance in radial ultrasonic rolling electrochemical micromachining. Int $\mathrm{J}$ Adv Manuf Technol. 107 (2020) 157-166.

[22]. T. Fujisawa, K. Inaba, M. Yamamoto, D. Kato. Multiphysics Simulation of Electrochemical Machining Process for Three-Dimensional Compressor Blade. Journal of Fluids Engineering. 130 (2008) 8 .

[23]. L. Ye, X. Zhu. Analysis of the effect of impact of near-wall acoustic bubble collapse micro-jet on Al 1060. Ultrasonics Sonochemistry. 36 (2017) 507-516. 
[24]. M. Laleh, F. Kargar. Effect of surface nanocrystallization on the microstructural and corrosion characteristics of AZ91D magnesium alloy. Journal of alloys and compounds. 509 (2011) 9150-9156.

[25]. D. Song, A.B. Ma, J.H. Jiang, P.H. Lin, D.H. Yang, J.F. Fan. Corrosion behaviour of bulk ultra-fine grained AZ91D magnesium alloy fabricated by equal-channel angular pressing. Corrosion Science. 53 (2011) 362-373.

[26]. D.Y. Wang, Z.W. Zhu, B. He, Y.C, Ge, D. Zhu. Effect of the breakdown time of a passive film on the electrochemical machining of rotating cylindrical electrode in $\mathrm{NaNO}_{3}$ solution. J. Mater. Process. Technol. 239 (2017) 251-257. 


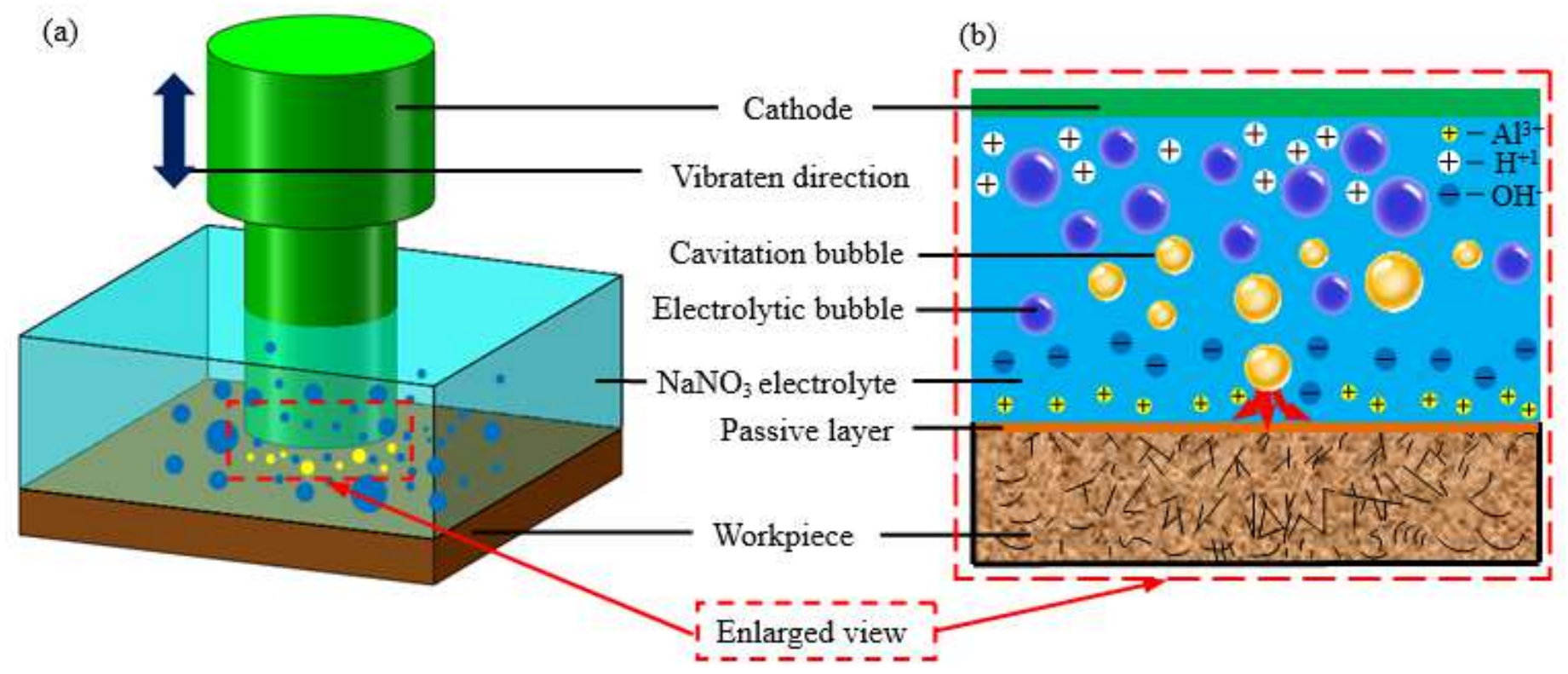

\section{Figure 1}

Schematic model of material removal during USEMM
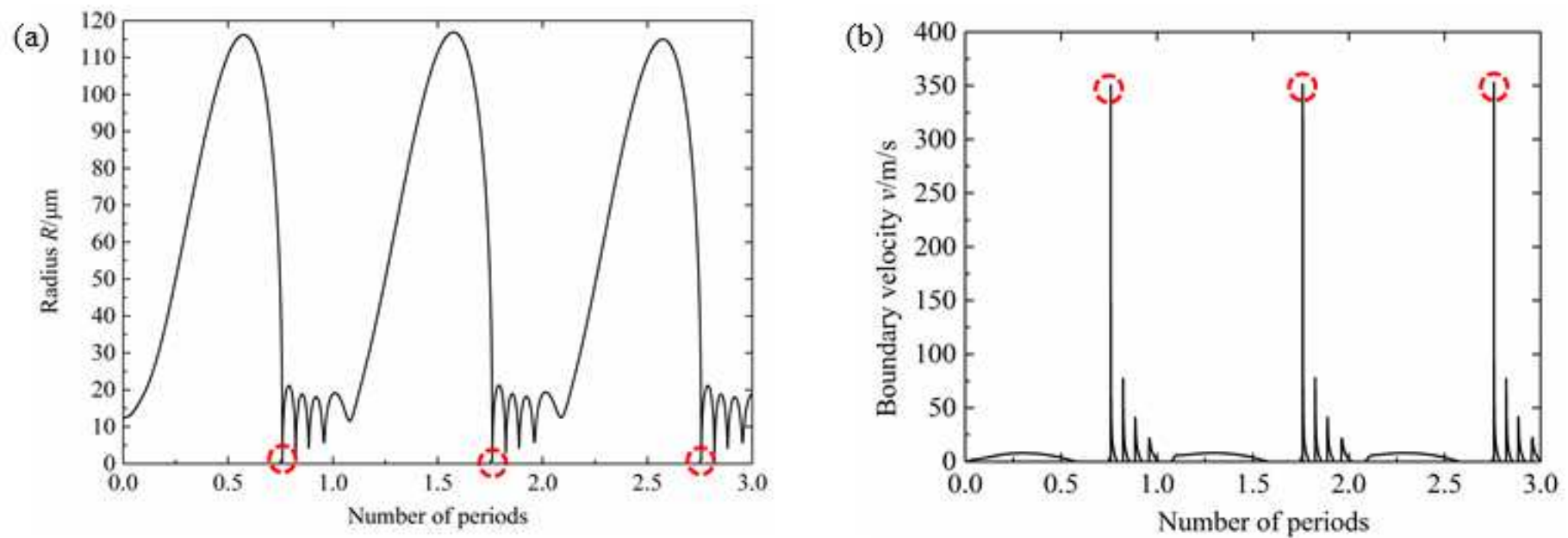

Figure 2

Analysis of cavitation bubble collapse (a) Radius, (b) Velocity 


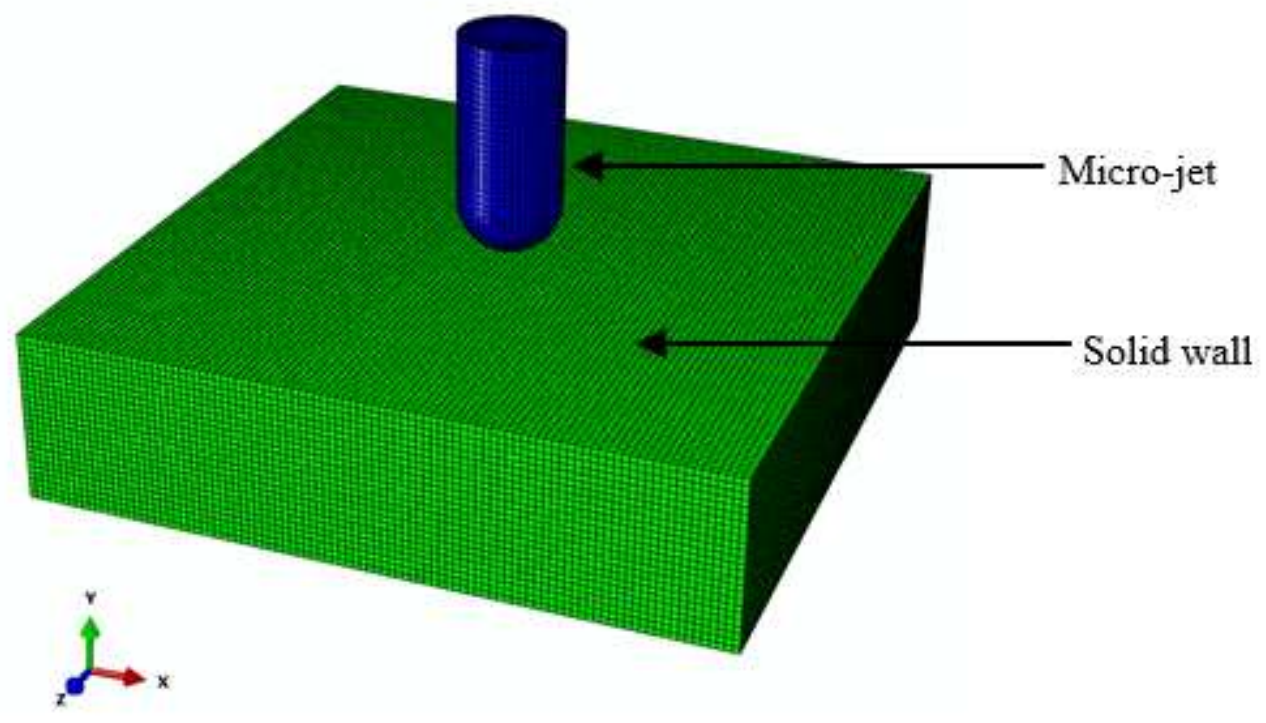

Figure 3

SPH-FEM coupling model of micro-jet 

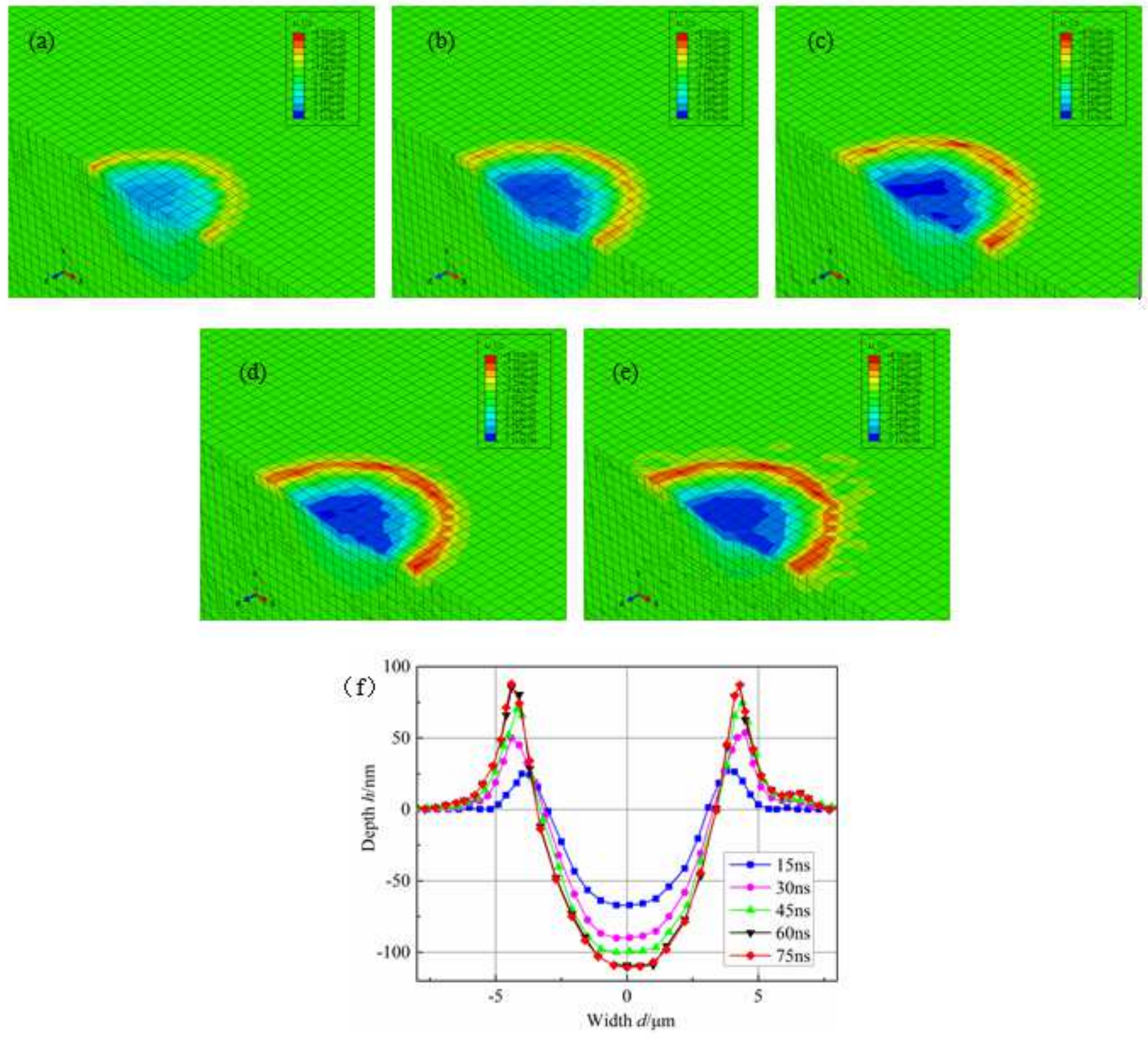

Figure 4

Simulation topography and profiles of cross-section at different time: (a) $15 \mathrm{~ns}$, (b) $30 \mathrm{~ns}$, (c) $45 \mathrm{~ns}$, (d) 60ns, (e) $75 \mathrm{~ns}$ 


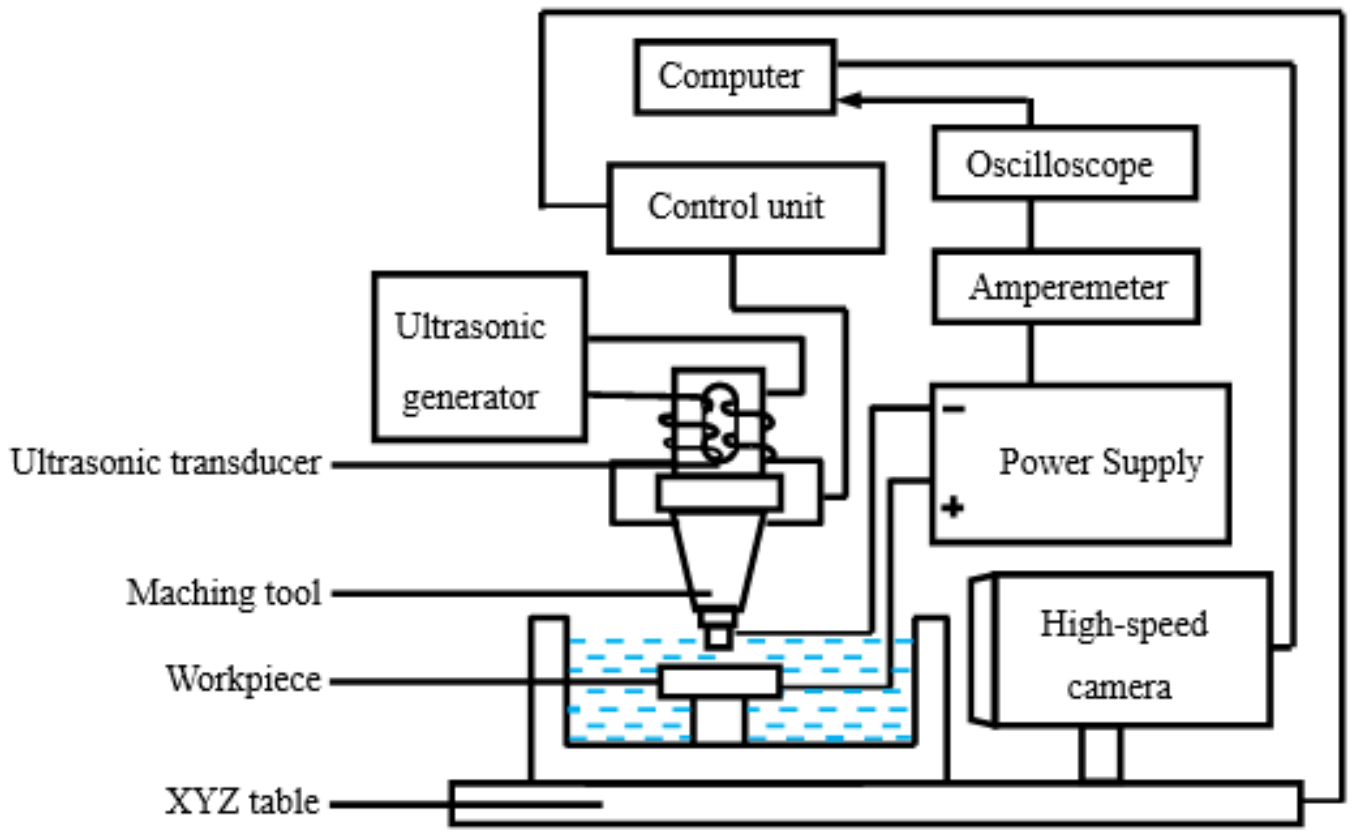

Figure 5

Schematic diagram of the experimental equipment 


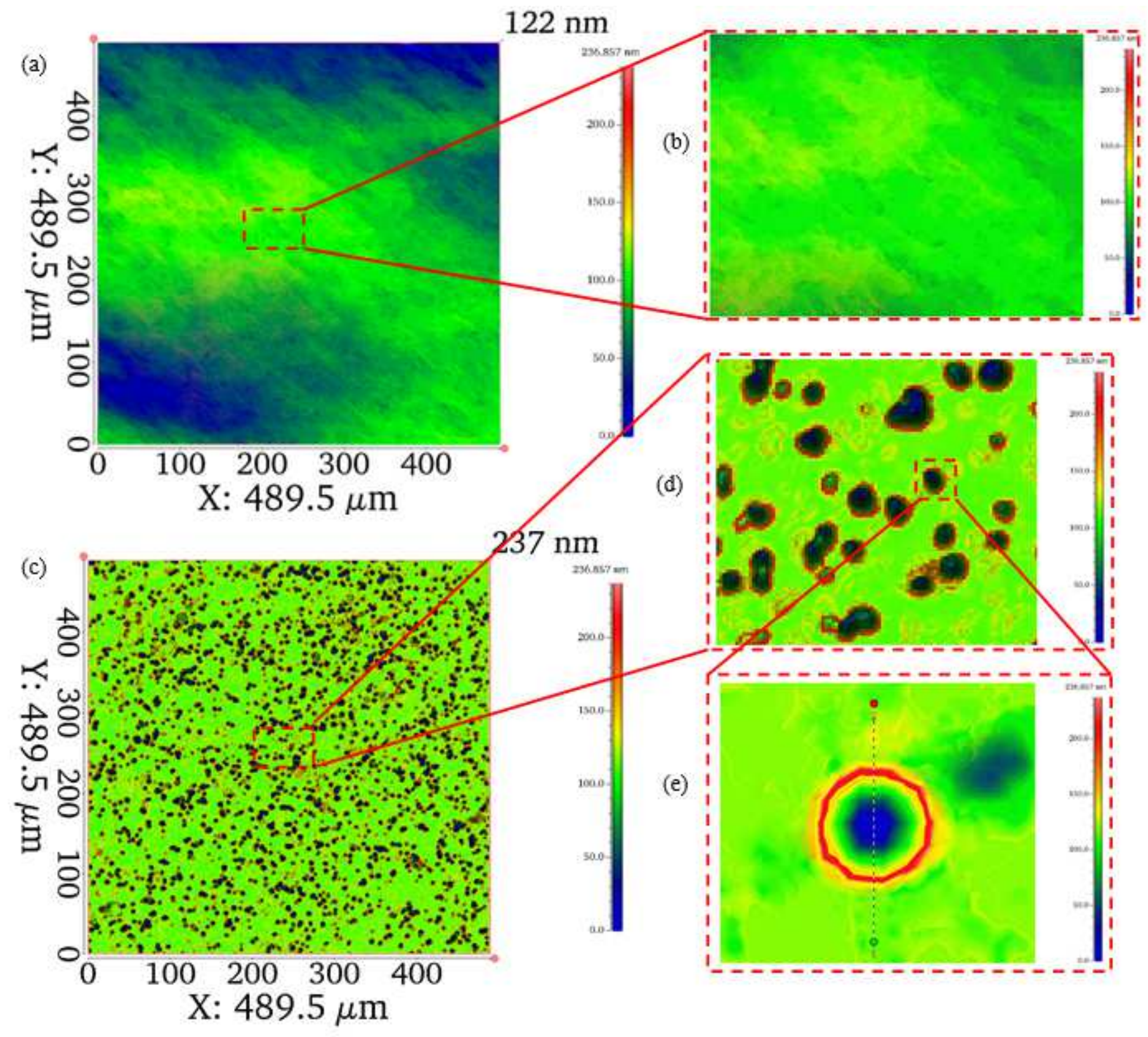

Figure 6

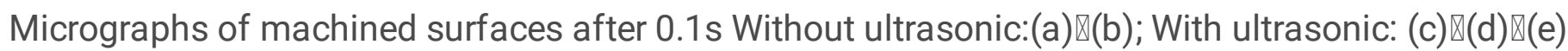




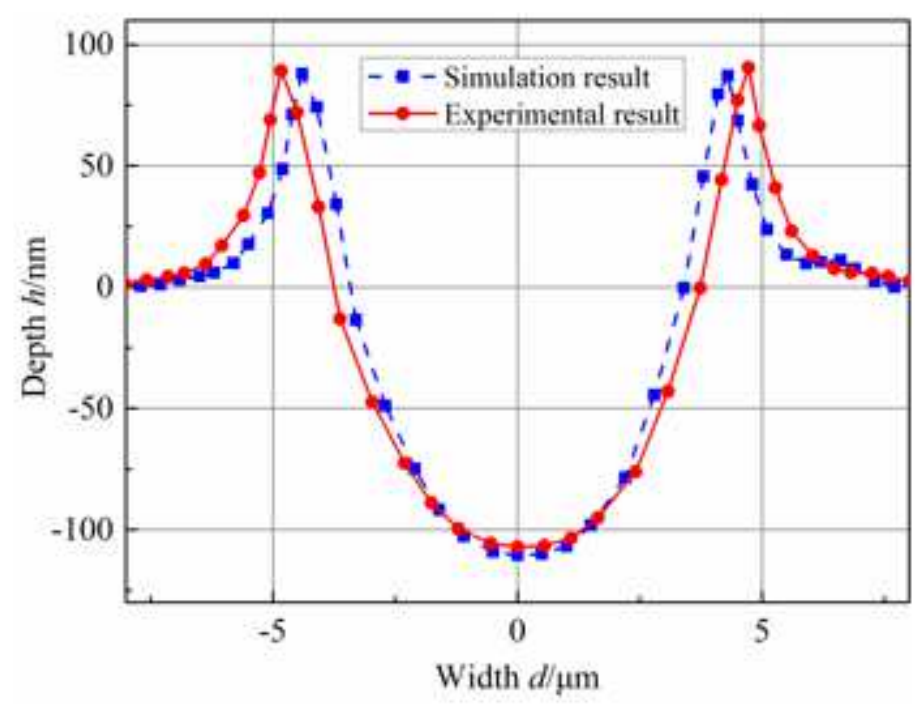

Figure 7

Experimental and simulation profiles of micro dimples with ultrasonic machining

(a)

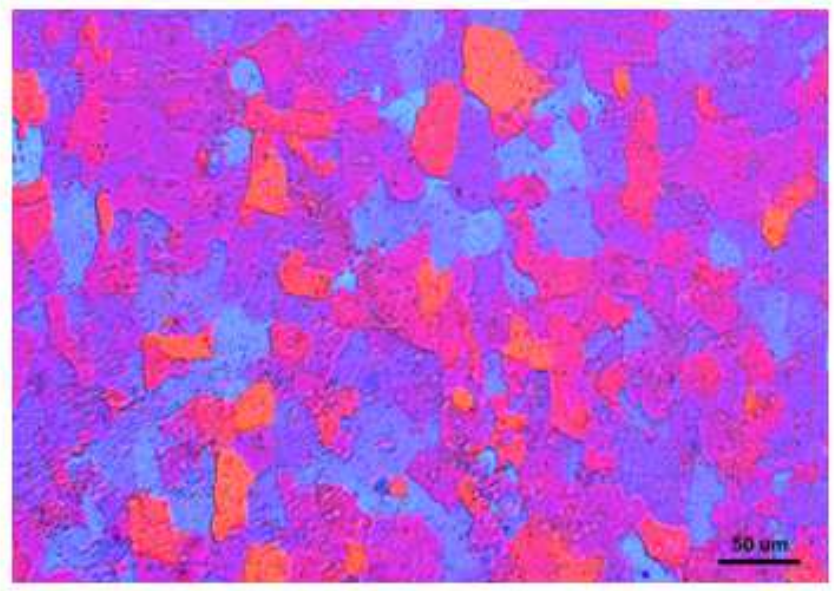

(b)

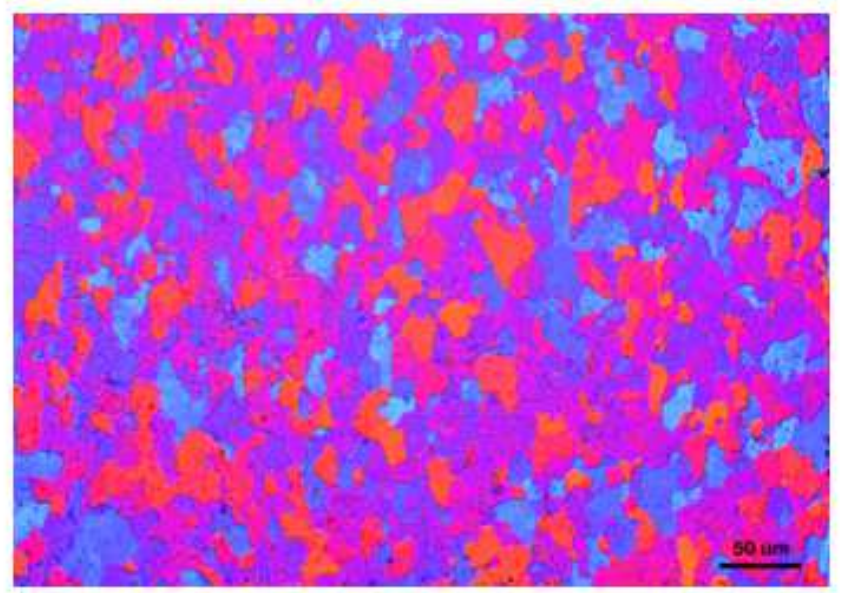

Figure 8

Grain size morphologies before and after ultrasonic machining 

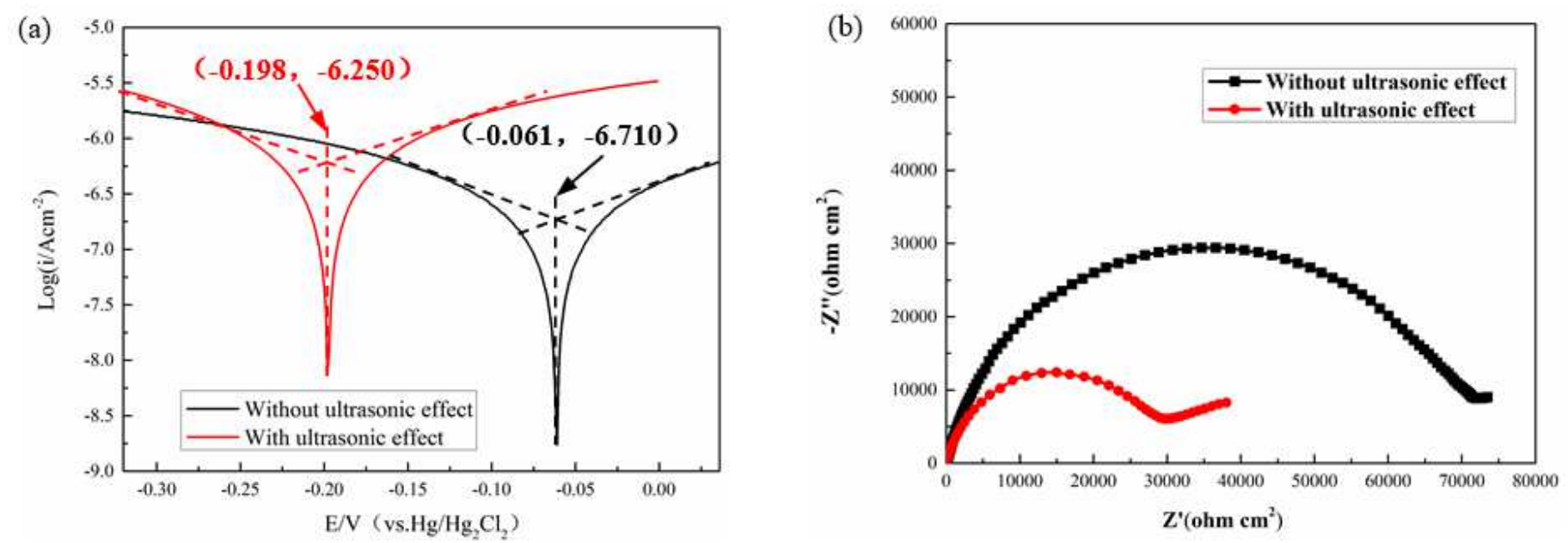

Figure 9

Polarization characteristic and Nyquist plots of impedance curves in different conditions

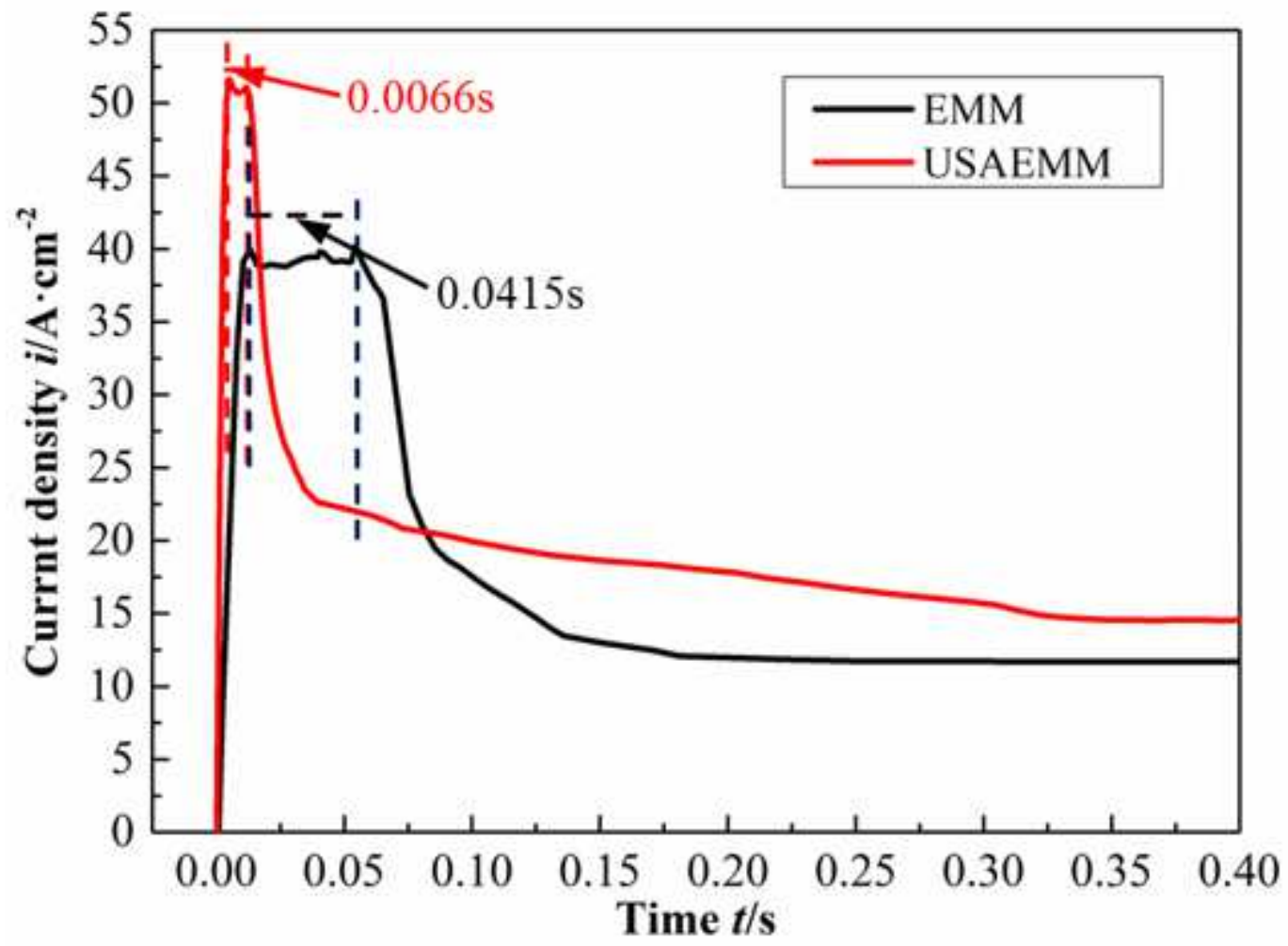

Figure 10

Current-time curve for the breakdown of the passive layer by EMM and USEMM 
(a)

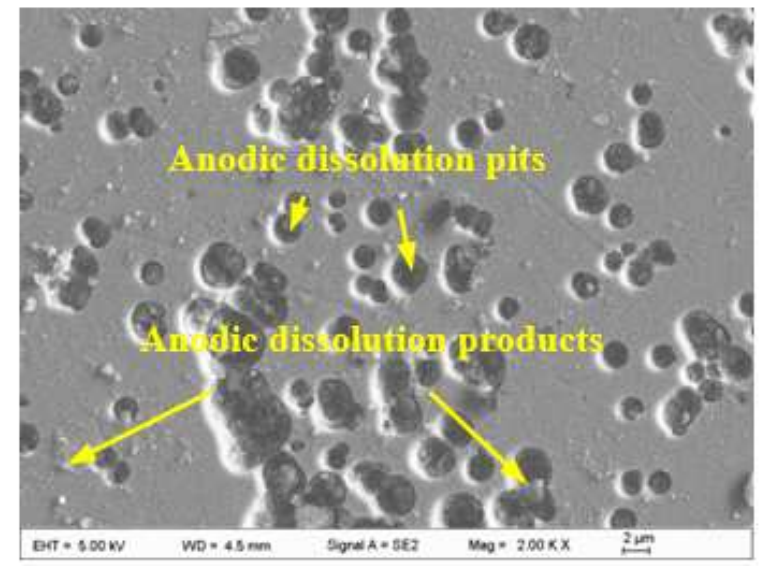

(b)

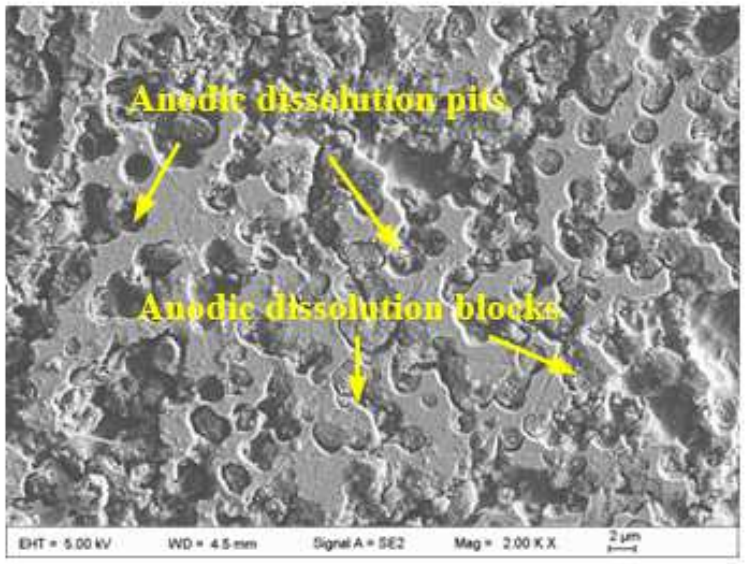

(c)

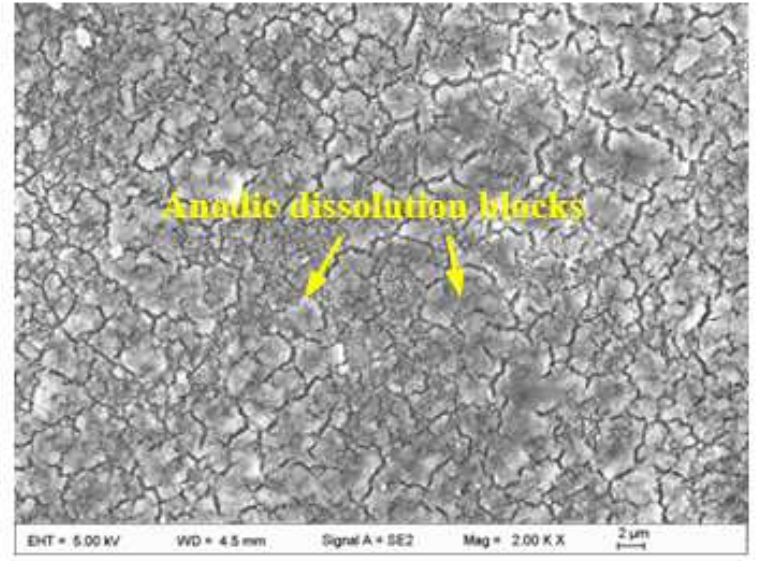

(d)

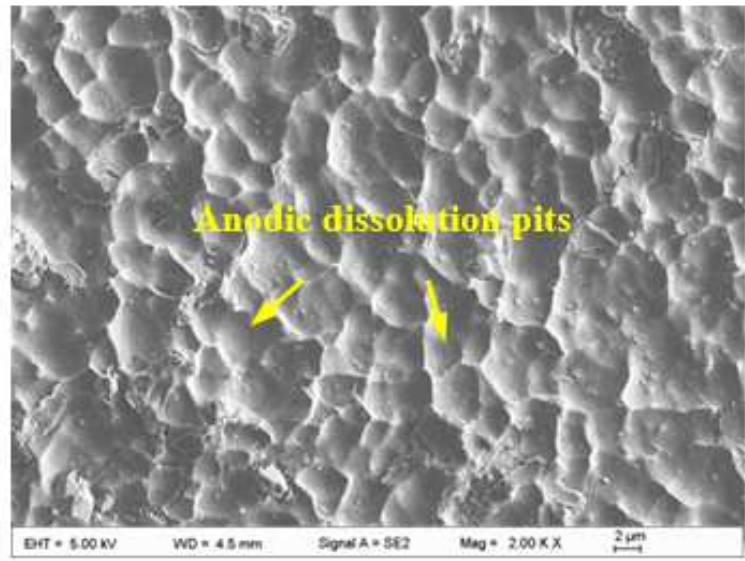

(e)

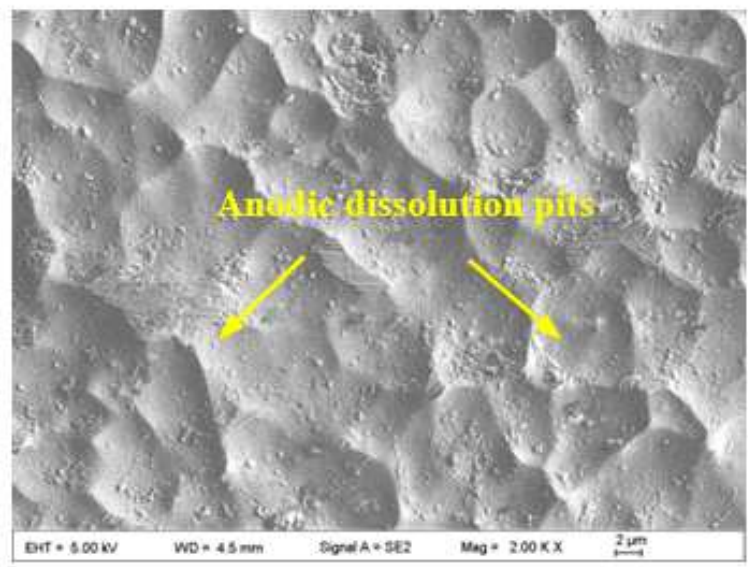

(f)

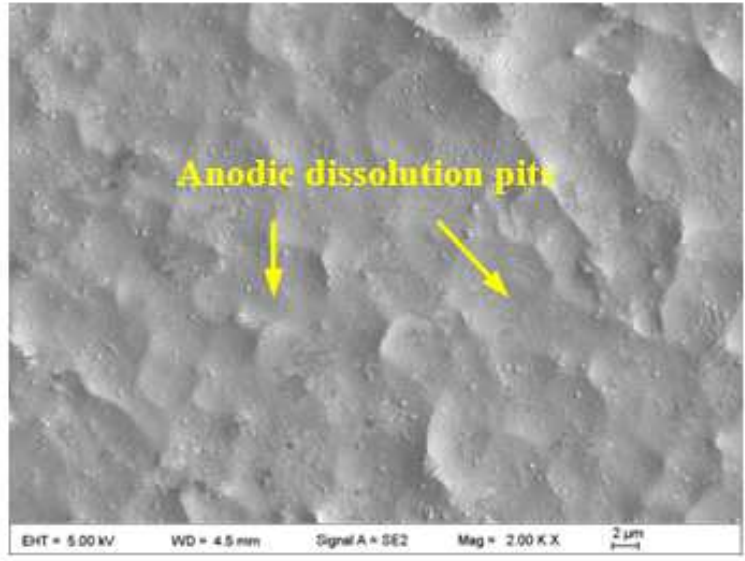

\section{Figure 11}

SEM images of surface structures anodically dissolved at different time $(0.1,0.2,0.6 \mathrm{~s})$ EMM:(a), (b), (c); USEMM: (d), (e),(f) 


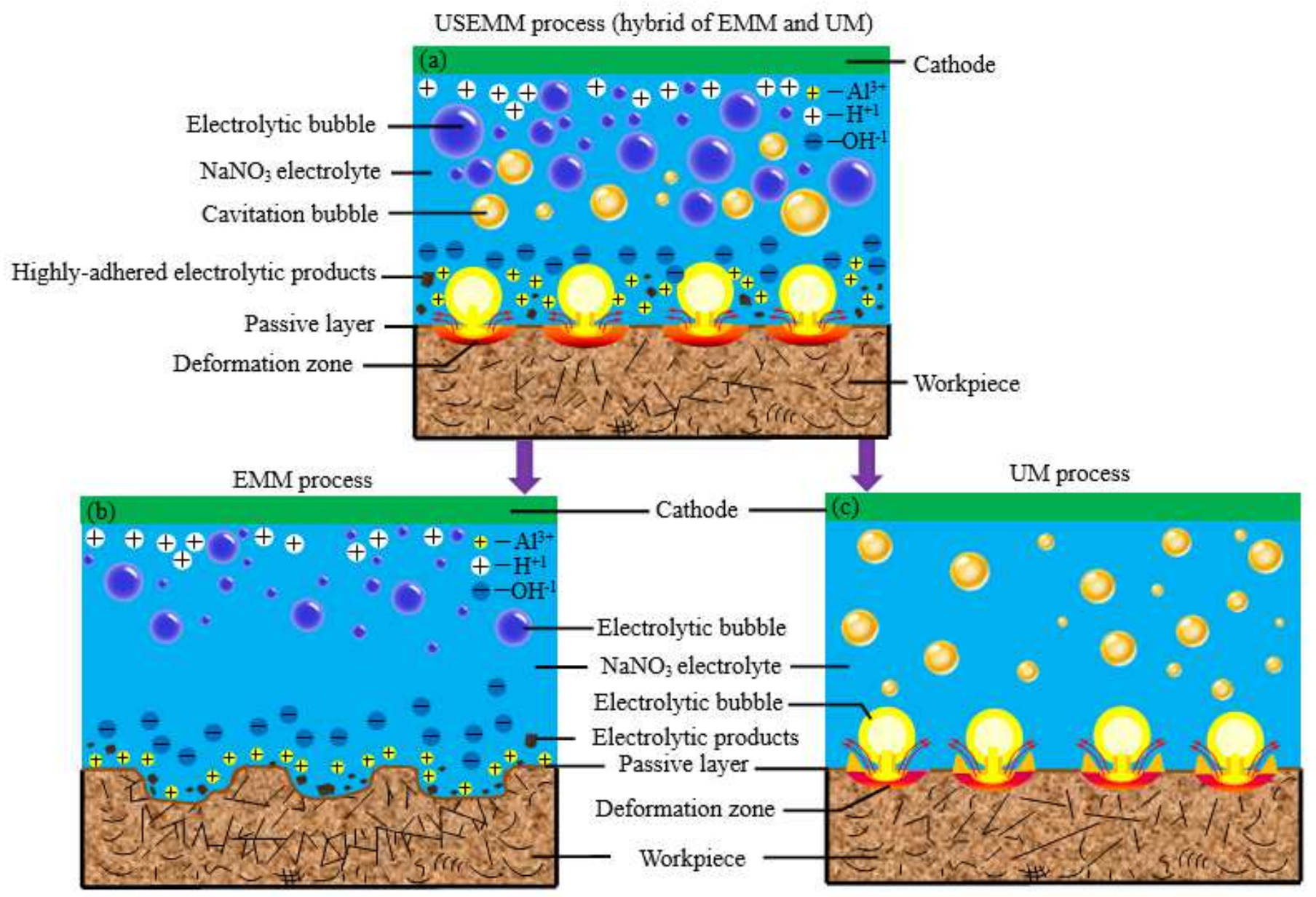

Figure 12

Schematic model of material anodic dissolution during USEMM USEMM: (a); EMM: (b); UM: (c) 